\title{
The Effects of a Dental Team and an Oral Health Protocol on the Oral Health of Residents Living in Long-Term Care Facilities
}

\author{
Stephanie F. Meredith \\ West Virginia University
}

Follow this and additional works at: https://researchrepository.wvu.edu/etd

\section{Recommended Citation}

Meredith, Stephanie F., "The Effects of a Dental Team and an Oral Health Protocol on the Oral Health of Residents Living in Long-Term Care Facilities" (2011). Graduate Theses, Dissertations, and Problem Reports. 3288.

https://researchrepository.wvu.edu/etd/3288

This Thesis is protected by copyright and/or related rights. It has been brought to you by the The Research Repository @ WVU with permission from the rights-holder(s). You are free to use this Thesis in any way that is permitted by the copyright and related rights legislation that applies to your use. For other uses you must obtain permission from the rights-holder(s) directly, unless additional rights are indicated by a Creative Commons license in the record and/ or on the work itself. This Thesis has been accepted for inclusion in WVU Graduate Theses, Dissertations, and Problem Reports collection by an authorized administrator of The Research Repository @ WVU. For more information, please contact researchrepository@mail.wvu.edu. 
The Effects of a Dental Team and an

Oral Health Protocol on the Oral Health of

Residents Living in Long-Term Care Facilities

Stephanie F. Meredith, B.S.D.H

\author{
Thesis submitted to the \\ School of Dentistry \\ at West Virginia University \\ in partial fulfillment of the requirements \\ for the degree of
}

Master of Science

in

Dental Hygiene

Christina DeBiase, Ed. D.

Robert Stuchell, D.M.D.

Alcinda Trickett-Shockey, D.H.Sc

Department of Dental Hygiene

Morgantown, West Virginia

2011

Keywords: Oral health; Long term care; Dental Professionals team;

Public Health Dental Hygienist 


\begin{abstract}
The Effects of a Dental Team and an Oral Health Protocol on the Oral Health of Residents Living in Long-Term Care Facilities

Stephanie F. Meredith

The oral health of residents living in long-term care facilities is poor. Dental teams and protocols need to be implemented for the facilities to help improve the oral health of the residents. The purpose of this study is to compare a long-term care facility that is implementing a dental team and protocol versus a facility that is not implementing a dental team and protocol. Oral examinations of 30 residents at each facility were conducted at baseline, one month and three month intervals. Data analyses were conducted using descriptive statistics and ANOVA $2 \times 3$ using SPSS software, to determine if any significant differences existed between the facilities, time of assessment and implementation of the dental team. Results indicated there is not a statistically significant difference in oral health scores between the two facilities or the time of assessment. Results also indicated there is not a statistically significant interaction between time of assessment and long-term care facility. However, improvements were noticed in the oral health scores of the facility with the dental team. It can be concluded from this study that there is a need for dental teams and oral health protocols, in conjunction with nursing teams, in longterm care facilities to help improve the level of oral health of the residents.
\end{abstract}


To my wonderful husband and best friend Rick, for your constant support, encouragement, love, and prayers. You truly are a gift and blessing in my life.

To my children...you are the sunshine in my life and I love you more than you could imagine! Thank you for not recognizing I was in school...I truly succeeded in reaching my goal.

To my parents, thank you for giving me the confidence to achieve my goals and for your continuous love and support.

To my father-in-law and mother-in-law...thank you... I am forever grateful!

In honor of my very dear Grandmother Maggie...may those living in long-term care have improved oral health and maintain the dignity they once desired. 


\section{ACKNOWLEDGEMENTS}

I would like to express my sincere gratitude to my thesis committee: Dr. Christina DeBiase, Dr. Robert Stuchell, and Dr. Alcinda Trickett-Shockey for your very valuable time, encouragement, and expert advice throughout this study. I appreciate each one of you and truly thank you. I also want to extend a special thank you to Mrs. Amy Funk and Mrs. Margaret Six for the time, dedication, and direction they showed me throughout my study.

I am grateful for the kindness and helpfulness of all the staff members at both long-term care facilities who graciously helped me throughout the study. A special thank you to Suzie for going above and beyond her duties and putting up with my crazy schedule to help me. This

study could not have gone so smoothly without her and all the other staff members who helped to make life easier for me.

I want to extend a special thank you to Aaron and Courtney Huffman. I want to thank Aaron for his understanding and love for statistics. I am extremely grateful for the time he dedicated to interpreting the statistics in this study and making sure I understood. A special thank you to Courtney for her support, encouragement, and guidance.

I want to thank my family for the constant support, understanding, encouragement, love and prayers they have shown me. I love, appreciate, and thank each one of you. Thank you to God for giving me the ability to reach my goals and for getting me through my Masters studies. 


\section{TABLE OF CONTENTS}

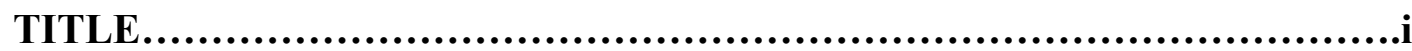

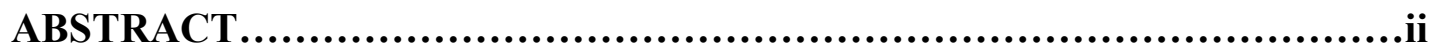

DEDICATION....................................................................iii

ACKNOWLEDGEMENTS.................................................iv

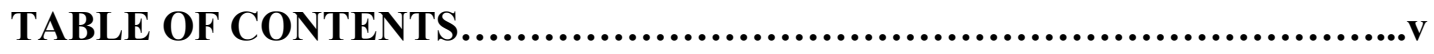

LIST OF FIGURES.............................................................vi

INTRODUCTION...................................................................1

REVIEW OF LITERATURE....................................................7

TEXT OF INVESTIGATION..............................................18

SUMMARY AND CONCLUSION..........................................41

RECOMMENDATIONS.........................................................42

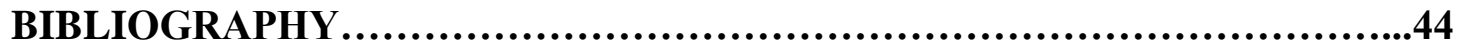

APPENDIX A................................................................46

APPENDIX B...................................................................48

APPENDIX C.......................................................................54

APPENDIX D...............................................................58

CURRICULM VITAE.....................................................60 


\section{LIST OF FIGURES}

FIGURE 1.................................................................22

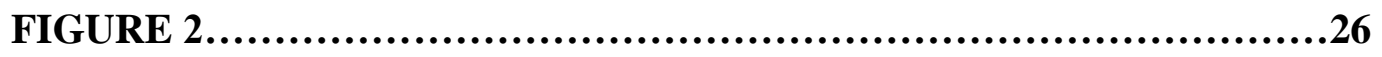

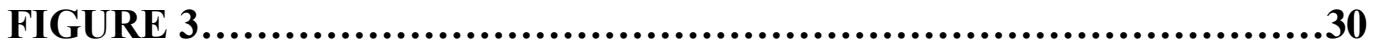

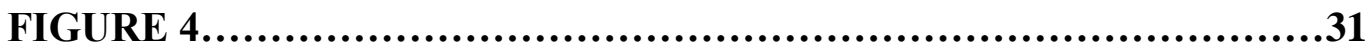

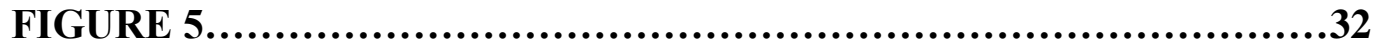

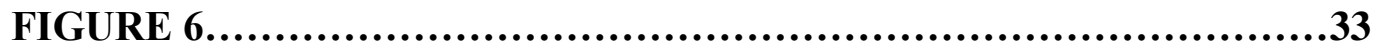

FIGURE 7...................................................................34

FIGURE 8...............................................................37

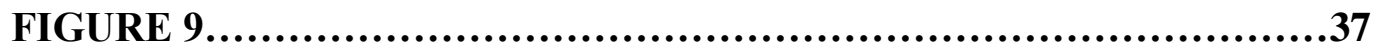

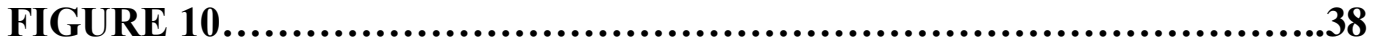




\section{Chapter One}

\section{Introduction}

Elderly long-term care residents have extensive oral disease and poor oral hygiene. This group suffers from the worst oral health of any U.S. population ${ }^{1}$. Bacteria found in the oral cavity can lead to systemic disease and can be especially harmful, and even fatal, to frail individuals. Maintaining good oral health is an important, yet underestimated way of enhancing the overall health and well being of the elderly living in long-term care facilities. In-service programs presented by dental professionals for the long-term care nursing staff must stress the importance of recognizing the link between good oral health and overall well being, and why it should be given the same priority as other health needs².

Oral health care in this population is usually compromised for several reasons. A large number of long-term care residents are unable to care for themselves, therefore it is the staff's responsibility to fulfill the residents' needs. Many residents lack the physical or mental capacity to maintain adequate levels of oral hygiene. They are susceptible to oral health neglect because these individuals are functionally dependent, medically compromised, and/or cognitively impaired ${ }^{3}$. The presence of systemic illness, including Alzheimer disease, arthritis, stroke, and the drugs used for their treatment can make oral health care more complicated. For individuals in advanced stages of Alzheimer's disease the caregivers have the main responsibility of providing the residents' oral health care ${ }^{4}$. Often performing oral care on these individuals can be challenging because the patient may react with anger, panic, crying, and despair. The caregiver 
often becomes frustrated and the patient no longer receives the oral care he or she deserves, resulting in the risk of developing threatening oral conditions.

Emerging evidence has demonstrated a strong link between the effects of chronic oral inflammation and overall health ${ }^{5}$. Patients living in long-term care facilities are often on medications which can adversely impact their oral health ${ }^{6}$. Certain medications can cause oral mucosal changes, bleeding, lichenoid reactions, tissue overgrowth, hypersensitivity reactions, and most commonly xerostomia, which often lead to an increase in carious lesions ${ }^{7}$. Infection from untreated carious lesions and periodontal disease can lead to pain, tooth loss, abscess formation, cellulitis, bacteremia, and systemic disease. Oral manifestations may be observed in nearly 100 systemic diseases that include respiratory infections, cardiovascular disease, infective endocarditis, brain abscesses, pancreatic cancer, stroke, diabetes, and nutritional problems. This is a bidirectional relationship with the underlying problem being inflammation ${ }^{5}$.

Bacteria from the oral cavity, teeth, and periodontal tissues can lead to pneumonia through silent aspiration. The elderly population is at a higher risk for developing complications from pneumonia than the average population. The risk of aspiration pneumonia is greatest when the patients suffer from periodontal disease, dental caries, and poor oral hygiene and are compounded with dysphagia ${ }^{8}$. The nutritional state of long-term care residents can be compromised as well. Pain from fractured, decayed, and abscessed teeth can lead to the inability and/or lack of interest to eat, therefore decreasing the nutritional intake of the residents. Residents with dentures are not exempt from poor oral health. Although the edentulous mouth does not contain periodontal pockets filled with microorganisms, it does contain higher amounts of yeast $^{8}$. The presence of yeast combined with debris coated dentures that are not removed routinely, can result in the development of candida infections in the oral cavity. Residents 
wearing removable dental prosthesis are also susceptible to sores as a result of poorly fitting dentures.

Approximately $75 \%$ of baby boomers will enter long-term care facilities with the majority of their natural teeth. Studies indicate that those residents who have good oral care require less in health care expenditures. Therefore, dental professionals should be part of a multidisciplinary team assembled by long-term care facilities to provide expert regular dental care and education to those assisting with the resident's care ${ }^{5}$.

\section{STATEMENT OF THE PROBLEM}

Limited in-service education for long-term care staff and lack of intervention by oral health professionals at long-term care facilities contribute to poor oral health and reduced quality of life among residents.

\section{SIGNIFICANCE OF THE STUDY}

Research has shown that the oral health of individuals living in long-term care facilities is less than acceptable. Poor oral health can lead to systemic conditions affecting the quality of life of this population. Oral health must be considered when managing the overall health of the elderly residing in long-term care facilities. The significance of this study is to determine the efficacy of oral health intervention at various levels involving a collaborative effort between the nursing staff and dental team. Current research investigates this relationship and its effects on oral health. 


\section{RESEARCH QUESTIONS}

Is proper education of the staff enough to improve the oral health status of residents living in long-term care facilities?

Does proper education of the staff need to be in conjunction with the implementation of a dental team to improve the oral health status?

Does a collaborative effort between the nursing staff and the dental team improve oral health?

Do the oral health scores of the residents improve over the three intervals of examinations with proper education?

Do the oral health scores of the residents improve over the three intervals of examinations with the implementation of the dental team and oral health protocol?

\section{DEFINITIONS OF TERMS:}

Oral Hygiene - the practice of keeping the mouth and teeth clean to prevent dental problems

Oral Mucosa - the lining of the mouth

Lichenoid Reactions - allergic reactions to the oral mucosa usually as a result of a certain medications

Hypersensitivity - abnormal sensitivity

Xerostomia - dry mouth

Caries/Carious Lesion - tooth decay, cavity

Gingivitis - inflammation of the gums and can lead to periodontal disease

Periodontal Disease - a disease that attacks the gum and bone around the teeth

Dysphagia - condition in which swallowing is difficult or painful

Abscessed Tooth - a painful infection in the root of a tooth

Edentulous - having lost teeth

Candida Infections - a fungal infection also know as thrush

Plaque - a soft, sticky and colorless deposit that is continually forming on teeth 
Calculus - a form of hardened plaque, also known as tarter

Angular Cheilitis - inflammatory lesion at the corner of the mouth

Ulcers - an open sore inside the mouth

Glossitis - inflammation of the tongue

Cellulitis - an inflammation of tissue

Bacteremia - presence of bacteria in the blood

Halitosis - offensive breath

Infective Endocarditis - an infection of the hearts inner lining

MRSA - (methicillin-resistant staphylococcus aureus) a bacteremia that is resistant to some kinds of treatment

$\mathbf{R D H}$ - registered dental hygienist

CNA - certified nursing assistant

OBRA - Omnibus Budget Reconciliation Act - provides regulations for long-term care facilities

\section{ASSUMPTIONS}

1. The residents living in the long-term care facilities depend on the nursing staff to assist the residents with their oral care.

2. The OHAT (oral health assessment tool) is a reliable tool to evaluate the oral health of the residents.

3. Residents may not be aware of their oral health status and/or oral health needs.

\section{LIMITATIONS}

1. The nursing staff may not remain the same from the beginning to the end of the study.

2. The subjects may become uncooperative at any interval of the study causing some of the oral health scores to become unusable. 
3. The subjects may not be able to complete all three evaluations due to illness, family requesting evaluations to cease, and death.

4. Not all the nursing staff who assist the residents with oral care may be available to attend the in-service training program although mandatory by the director of nursing.

\section{DELIMITATIONS}

1. Residents were randomly chosen to provide an accurate representation of the population.

2. Participants selected all resided in a long-term care facility. 


\section{Chapter Two Review of Literature}

OBRA law regarding dental services mandated in nursing home facilities consists of "an annual inspection of the oral cavity for signs of disease, diagnosis of dental disease, dental radiographs as needed, dental cleaning, fillings, minor dental plate adjustments, smoothing of broken teeth, and limited prosthodontic procedures such as impressions of dentures and fitting of dentures." In addition, scheduling of appointments, transportation to and from dental services, and annual in-service staff training are also components of this law. ${ }^{21}$ Although this law exists, extensive amounts of literature label the oral health of long-term care residents as poor.

Literature also supports the need for good oral care and how it contributes to overall health. Poor oral health care is related to staff knowledge, attitude, time, understaffing, and patient cooperation. Research has also been done to determine the efficacy of education programs and the implementation of dental teams on the oral health of this population of people.

\section{Oral Health Neglect}

Poor oral health in the elderly can lead to life threatening conditions such as malnutrition, brain abscesses, heart disease, joint disease, and pneumonia. It also affects mortality, overall health, nutrition, digestion, speech, and quality of life. Long-term care staff tends to not recognize the importance of poor oral health and attention to this subject is low on the priority list ${ }^{2}$. 
The first literature review, "Status of oral healthcare in long-term facilities," proposed oral care neglect occurs at significant levels in long-term care settings. Three investigations were analyzed. The first investigation consisted of 442 residents. Alarming findings revealed $65 \%$ of the denture population had visible amounts of plaque, calculus, and stain. Nearly $53 \%$ had denture-induced pathology that needed further treatment of which the staff responsible for dental care was unaware. The second investigation of a random sample, which included 653 residents from 41 long-term care facilities, revealed more than one third had denture stomatitis. There were thick layers of plaque on more than $50 \%$ of those wearing dentures. Nearly $20 \%$ were using dentures that were broken or had missing parts. Tooth decay was present in 55\% and $11 \%$ had severe periodontal disease resulting in advanced mobility of the teeth. The third investigation of 201 elderly nursing home subjects indicated two thirds having significant amounts of plaque and calculus. Severe gingivitis, ulcerations, and bleeding occurred in $25 \%$. Residents who depended on the nursing home staff for their oral care had significantly more amounts of plaque and gingivitis. Other findings included angular chelitis, ulcers, glossitis, xerostomia, and sore tongue. In conclusion for this article, higher levels of registered nurses and nursing hours related to improved oral care. Lower nursing levels and aides resulted in poorer oral care. The article also concluded the oral disease epidemic in the residents of long-term care has been neglected for too long, and hoped to increase the importance of good oral care in residents $^{2}$.

Residents suffering from dementia seem to have more oral care problems than residents without dementia. Anderson, Rejnefelt, and Renvert conducted a literature review reporting on the combined results of four studies dealing with the oral health status of residents suffering from dementia. The results showed carious lesions in 59\% of moderate dementia 
individuals and $68 \%$ of severe dementia. Significantly more teeth had non-treatable carious lesions in those with severe dementia. Nearly $68 \%$ of Alzheimer patients had tooth surfaces covered with plaque. A longitudinal study was conducted comparing individuals with Alzheimer's and a healthy control group. At the completion of the study no differences were found in regard to caries, pocket depth, attachment loss, or mucosal changes. There were however significant differences between the two groups in regard to plaque, calculus, and bleeding. The Alzheimer's group had increased amounts at each examination. They suffered from more carious lesions, periodontal disease, accumulations of plaque and calculus, and bleeding. It also showed oral health problems increased with the more severe cases of dementia ${ }^{6}$.

A study was conducted on "oral health in Florida nursing homes," which further supports the statement of problem. The purpose of the study was to measure the oral health and hygiene of 265 South Florida nursing home residents between the ages of 45 and 98 . Results showed $79.6 \%$ of the residents had calculus and the remaining residents were edentulous. More than half the residents had oral problems. Gingivitis was most common (36.6\%), followed by caries, and tooth fracture. Oral health problems increased with age. Oral health neglect affected almost all of the nursing home residents. Proper education and training from dental professionals was needed to improve the oral health of the elderly ${ }^{3}$.

Coleman et al. (2006) performed a study titled "oral care provided by certified nursing assistants in nursing homes." The significance of the study was to assess the oral care provided by Certified Nursing Assistants (CNAs) for the residents of long-term care facilities. A convenience sample of 67 residents was used with oral care provided by 47 CNAs. The findings were alarming. Only 11 residents had their teeth brushed, 5 had their teeth physically brushed by 
the CNA, 6 brushed their teeth with supervision, and 8 had their teeth swabbed with a toothette, which is considered inappropriate. No one had their teeth brushed for the recommended two minutes, with the average brushing time being 16.2 seconds. When residents brushed on their own they were always cut short by verbal directions to quit. The same 11 residents whose teeth were brushed were given the opportunity to rinse with water only. Mouth rinse and floss were never offered or used. Clean gloves were never used. All oral health care observed was done immediately following assistance in the restroom and gloves were never changed. Treatments were compared with documentation which was only available for $9 \%$ of the observations. Documentation indicated oral care was performed on all residents even when none was observed $^{1}$.

There have been studies on the correlation between oral bacteria and respiratory disease. "Oral bacteria influenced by the functional status of the elderly people and the type and quality of facilities for the bedridden" examines the bacterial species in the oral cavity of elderly subjects staying in two long-term care facilities. The study showed a correlation between an increase in bacteria, especially significantly higher detection of methicillin-resistant Staphylococcus aureus (MRSA), with functional status, physical function, and nutritional state. These residents were already susceptible to infection because of decreased immune response. When combined with large deposits of plaque, with evidence of MRSA, this population of people suffered from secondary infections that could be life-threatening. The need for improved oral health continues to be of great importance and a major problem in long term care facilities ${ }^{9}$.

A significant amount of studies have linked oral and systemic disease. The elderly are at greater risk of developing medical conditions including aspiration pneumonia. Poor oral health contributes to the development of aspiration pneumonia which results in higher mortality rates. 
There are economic consequences as well. Nearly $\$ 8$ billion dollars are spent annually treating aspiration pneumonia. The worst part of the situation is oral diseases are preventable and treatable and therefore long-term care residents' overall health should not be compromised ${ }^{11}$.

\section{Oral Health Education and Dental Professionals}

Chronic gingivitis, caries, missing teeth, chewing difficulties, pain, and discomfort have become commonplace in long-term care facilities. These conditions have been associated with malnourishment of already frail individuals. In order to fight the oral health problem in longterm care, oral health-related education needs to occur. Typical education offered to nurses and CNA's consists of lectures or seminars presented by dental professionals. However, studies have been inconclusive on the effects of the educational methods. Some methods seem to benefit the residents; some enhance the knowledge of the nurses; whereas others give no noticeable impact to anyone. Even more unfortunate is when benefits were noticed, usually they were short lived ${ }^{10}$. "Provision of mouth-care in long-term care facilities: an educational trial," studied the effects of CNAs having unlimited access to health related advice and its effects on the oral health of residents in long-term care. This randomized clinical trial included fourteen matched facilities that were randomly assigned to an active or control group. Both groups were evaluated at baseline and again at three months. CNAs in the active group participated with a full time nurse educator in an oral health care seminar, and had unlimited access to the educator for oral health advice for the entire three month trial. CNAs in the control group participated in a similar seminar with a dental hygienist, but received no additional advice. Upon completion of the study results were not significantly different from baseline in either group. Results indicated that education did not have an impact on the oral health of the residents ${ }^{10}$. 
"Oral health coordinators in long-term care - a pilot study," tested curricular and systems approaches to improving the oral health care of residents living in long-term care. Three facilities were chosen and were evaluated at four intervals. An oral health coordinator (OHC) was appointed at each facility. The OHCs were existing staff members who were responsible for acting as a liaison between nursing and dental staff, providing resources for nursing assistants, and ensuring the staff provided residents with daily oral care. In addition to the creation of the $\mathrm{OHC}$, the nursing assistants were trained in oral care through a trainer-based program and job shadowing. The education consisted of information on basic oral health, the oral/systemic disease connection, dental caries (with emphasis on root caries), behavioral management, and brushing techniques ${ }^{11}$.

The job shadowing required the OHCs to accompany each nursing aide as he/she provided oral care to residents. The trainer offered advice and demonstrated techniques to increase their confidence in providing oral care to the residents. Two dentists were responsible for conducting the baseline, 2, 6, and 12 month evaluations. Results showed significant improvement in oral hygiene among the study subjects. The more interested and dedicated the OHC, the greater improvements in oral health ${ }^{11}$.

People living with dementia and Alzheimer's disease (AD) are unable to communicate their discomforts. "Oral hygiene care for residents with dementia: a literature review," reports oral health in the elderly is often misunderstood and neglected. Dental professionals examined residents from a sample of nursing homes in the U.S. and concluded $60 \%$ of those examined had dental pain, but geriatricians concluded only $30 \%$ had dental pain. The difference can be attributed to dementia and $\mathrm{AD}$ patients communicating their discomforts in behavioral changes as well; neglecting to eat, disinterested in food, chewing of the lip, pulling of the face or mouth, 
not wearing dentures, bruxing of the teeth and dentures, aggression, and alteration of activities. It is critical to practice good oral care with these residents to prevent medical complications such as pneumonia and bacterium, manage side effects of medication, speech problems, swallowing problems, and manage consequences of medical conditions ${ }^{4}$.

The study further stated successful examination can be performed by the nursing staff; however they do not have the qualifications of a dental professional to make an adequate dental assessment. Long-term care facilities do not implement dental professionals mainly due to costs. They are usually called upon when treatment is needed. Experts recommend that dental assessments be performed during admission of a resident by the staff and then by a dentist at regular intervals ${ }^{4}$.

Education of the staff is of significant importance to maintain good oral health. "Oral health care - a low priority in nursing," addresses the issue of proper education for the long-term care staffing. Interviews were used to assess the nurses' attitudes toward oral health care. The nurses stated failure of knowledge, failure of routines, failure of support, and increased workload were all inner and outer circumstances that affected oral health of the residents. Nursing staff felt they had inadequate education in oral health. Very few had post-graduate instruction in oral health. The nursing staff expressed the need for regular continuing education in the area of dental care ${ }^{12}$.

The long-term care staff was to perform oral health care on the residents twice a day however, there was no protocol for routine. Staff members all performed varying degrees of homecare and the day and night shift had no communication about services performed. The staff reported patients with dentures were easier to assist than those with natural teeth. The residents suffering from dementia and Alzheimer's disease created a problem because they relied on the 
staff exclusively to meet their oral health needs. Personal experiences played a part in the neglect of the health care. Cooperation of the patient, fear of being bitten, disgust with the condition of the residents' mouths, and worrying if it is right or wrong to force dental care on someone all contributed the oral care being a low priority ${ }^{12}$.

The nursing staff felt the oral care of the residents should also be a concern of the residents' families. However, in relation to dental care, the nursing staff became the spokesperson for the resident. Families rarely commented and when dental visits were brought up the family often declined for financial reasons. Dental teams seldom visited the nursing homes although the staff felt having dental teams perform regular visits would be of significant importance $^{12}$.

Long-term care staff members rarely receive any oral health education despite the fact that many have expressed a need. As shown in the study "oral health care education and its effect on caregivers' knowledge and attitudes: a randomized controlled trial," caregivers generally have positive attitudes toward oral health care, yet fail to overcome barriers. For this study twenty-two long-term care facilities were selected and all caregivers were encouraged to participate, however they were not required. Oral health knowledge and attitudes of caregivers were assessed using questionnaires. Knowledge was tested at three intervals with response rates being $80.5 \%, 81.1 \%$, and $77.2 \%$ respectively. Combined scores for correct responses rose significantly from baseline to third assessment. Nearly $90 \%$ of caregivers knew that brushing improved gingival conditions, sugary foods increase the prevalence of carious lesions, and protective gloves should be worn when brushing residents' teeth. Only $20 \%$ knew that plaque related gingivitis is often times painless. Following the intervention, there was clear evidence of caregivers' behavioral change that contributed to improved oral health status in nursing home 
residents $^{13}$.

"Oral bacteria and clinical variables in dependent individuals at a special facility" determined if the oral flora present in the oral cavity of thirty three long-term care residents were related to other health problems, and to classify the residents on different risk levels. Oral examinations were performed by dental hygienists, three day food records were kept, and an oral micro bacterial analysis was conducted. Results showed high risk levels correlated with severe functional impairments which in turn related to more natural teeth, assistance with oral hygiene, nutritional problems, and nutritional supplements. Aside from the microbial analysis, there was a correlation between the number of medications and mucosal infections and oral health. Seven residents had both poor oral hygiene and oral health. Twenty-two residents had acceptable oral hygiene and oral health. One resident had poor oral hygiene and acceptable oral health. Four residents were referred for further dental care in addition to the oral health care of the facility. Only one resident had poor oral health. Only one resident had to be referred to a dentist while the rest of the residents were able to be treated by the dental hygienist on $\operatorname{staff}^{14}$.

Long-term care facility staff training is a crucial part to the improvement of oral health in the residents. "Effectiveness of health care worker training on the oral health of elderly residents of nursing homes" measured the effects of properly educating the staff so they have the ability to assist the residents with oral care. Seventy-eight residents were selected from five long-term care facilities. A baseline assessment was performed and revealed $83 \%$ of the residents having gum disease and denture stomatitis was present in $78 \%$ of the edentulous residents. Only one long-term care facility had any oral care record for their residents at baseline. Intensive staff training on oral health was conducted by a dental professional and was well received. Post-training examinations were conducted and there were significant 
improvements in the oral health of the residents. The majority of residents' oral care was

performed by staff members, significant improvements in denture hygiene and a reduction in the number of residents who wore dentures overnight, prevalence of oral disease dropped, and there were significant reductions in angular chelitis and denture stomatitis ${ }^{15}$.

An additional study, "Oral health education for nursing personnel; experiences among specially trained oral care aides: one year follow-up interviews with oral care aides at a longterm care facility," evaluated the relationship between awareness, knowledge, attitude and health behavior. The staff members who were responsible for the oral care of the residents participated in oral healthcare education lectures and attended a dental clinic one day per week over a four week period to gain experience in dental care. They returned to their current work and were interviewed one year later. The results indicated, apart from hesitant residents and occasional lack of commitment from co-workers, the workers involved with the oral care of the residents felt responsible for proper care. Upon completion of the training the workers felt they had the courage, the capacity to cope with reality, empathy, and felt they had expert competency ${ }^{16}$.

"Oral cancer screening and nursing home dentists," suggests dental staff at long-term care facilities not only have proper education, but stay current on knowledge and skills as well. A correlation was established between less than satisfactory oral care and higher incidences or oral cancer. Dentists may vary on their diagnosis depending on their current knowledge of the situation, cooperation, and time available for assessments. Currently there are eight long-term care facilities to one dentist who may or may not work fulltime. This creates a barrier to access oral healthcare. An increase in training seminars and dental professionals available on staff would help to improve the oral health status of individuals living in long-term care facilities ${ }^{17}$.

"Maintaining oral health in the nursing facility" examines the importance of having 
registered dental hygienists (RDH) acting as oral health liaisons (OHL) in long-term care facilities. Certified nursing assistants are trained to assist and/or monitor a resident's oral hygiene. CNAs are not always comfortable with assisting the residents because a poorly kept mouth can often be intimidating and repulsive therefore compromising the quality of care the resident receives. By enlisting the services of a $\mathrm{RDH}$ as an OHL, a facility could hope to improve the oral health of the residents. The OHL could instruct the staff members and capable residents on the basics of daily mouth care and why it should be a routine standard of care. Beyond providing oral health education, the OHL would be trained to recognize any problems they discover during examinations. The OHL would facilitate scheduling an appointment with a dentist or advise the nursing staff to do so. The RDH could provide services on a full or part-time basis, scheduled, rotational, or on-call basis. The article concluded in saying appointing a registered dental hygienist as an Oral Health Liaison is a cost-effective way to increase access to proper oral care in long-term care settings, and to help the residents maintain their quality of life and dignity ${ }^{18}$. 


\section{Chapter Three}

\section{Text of Investigation}

Two long-term care facilities were chosen for this study. The facilities granted approval for the investigator to conduct the study. Approval was granted by West Virginia University Institutional Review Board for Protection of Human Subjects for the study to be conducted at Facilities A and B in West Virginia (Appendix A). Thirty residents were randomly chosen at each facility and consent forms were completed for each participant (Appendix B). Consent was granted by the resident if they were able to grant their own consent or by the power of attorney on record for each participant. Those granting consent were asked to complete a brief questionnaire relating to the oral health of the participant (Appendix C). Results of the questionnaire are shown using descriptive statistics displayed in bar graphs (Figures 5-7).

The study consisted of baseline findings, one month and three month evaluations. The oral health assessment tool (OHAT) was the assessment tool chosen to evaluate the resident's oral health status (Appendix D). "The OHAT was evaluated as being a reliable and valid screening tool for use in residential care facilities, including those who are cognitively impaired

residents ${ }^{19}$." Evaluations consisted of visual exams using a mirror only and were conducted by the investigator. The investigator had access to medical records for each participant. Facility A was in the process of establishing a dental team in the facility. The dental team would have the ability to perform dental cleanings on the residents as well as minor dental services in the facility. The investigator conducted baseline evaluations with the dentist leading the dental team 
in the facility, before the dental team was implemented. One month evaluations were conducted to follow-up with the dental team's recommendations. The oral health interventions included dental cleanings at the facility, oral hygiene instruction specific for each resident, denture repairs, denture relines, extractions, and restorations. Three month evaluations were conducted following in-service trainings to the staff presented by the investigator. Baseline evaluations conducted by the investigator were established at Facility B. One month evaluations were also conducted. In-service trainings were presented to the staff and follow-up evaluations were conducted three months after the initial evaluation.

The same in-service training program was presented at each facility with two sessions being offered at each facility. The day and afternoon staff attended the mandatory instructional sessions because they were responsible for assisting with the oral care of the residents. Each inservice training was thirty minutes in length and consisted of a power point presentation with information on the importance of good oral health, the relationship to overall well being, and the risks associated with neglect. Visual demonstrations were also conducted. Thirty random nursing staff members from each facility were asked to complete a questionnaire relating to their viewpoints on providing oral care to the residents (Appendix C). Results are showed using descriptive statistics displayed in bar graphs (Figures 3-4).

Five participants from Facility A expired before completion of the study, resulting in a comparison of 25 residents from baseline to final evaluation. Three residents from Facility B were completely uncooperative throughout the study at all three intervals, and one resident was unable to complete the study due to illness. Subsequently, the oral health status of 26 residents was compared at baseline and final evaluation.

Descriptive statistics represented by pie charts were used to compare individual 
categories in the Oral Health Assessment Form from baseline, to one month, to final evaluation in each facility (Figures $1.1-2.24)$. Factorial ANOVA $(2 \times 3)$ was used to determine if there was a statistically significant difference in the overall oral health scores between the two facilities and among the three periods of assessment (Figures 8-10). SPSS (Statistical Package for the Social Sciences) was used to conduct the statistical test. SPSS is among the most widely used software for data anaylsis ${ }^{19}$.

\section{NULL \& ALTERNATIVE HYPOTHESES:}

$\mathbf{H}_{\mathbf{0}}$ \#1: There is no statistically significant difference in overall oral health scores among the three times of assessment.

$\mathbf{H}_{\mathbf{a}}$ \#1: There is a statistically significant difference in overall oral health scores among the three times of assessment.

$\mathbf{H}_{\mathbf{0}}$ \#2: There is no statistically significant difference in overall oral health scores between the two long-term care facilities.

$\mathbf{H}_{\mathbf{a}}$ \#2: There is a statistically significant difference in overall oral health scores between the two long-term care facilities.

$\mathbf{H}_{\mathbf{0}}$ \#3: There is no significant interaction between time of assessment and long-term care facility.

$\mathbf{H}_{\mathbf{a}} \# \mathbf{3 :}$ There is a significant interaction between time of assessment and long-term care facility.

\section{RESULTS}

The researcher used the OHAT (oral health assessment tool) to evaluate the oral health of the residents. The assessment was conducted by evaluating the oral health status of eight areas. The areas of assessment included the lips, tongue, gums and tissues, saliva, natural teeth, dentures, oral cleanliness, and dental pain. A score of zero was given to areas that presented as healthy. A healthy status was defined as free from infection, no swelling present, no broken and 
decayed teeth, free of food particles or tarter on dentures or natural teeth, moist tissues, and no verbal or physical signs of pain. A score of one was given to areas where change in oral health was noted. Changes in oral health would be defined as dry tissues, one to three decayed or broken teeth, one broken area on a denture, no name on a denture, denture only worn for one to two hours daily, food particles or debris in one or two areas of the mouth, and/or verbal/behavioral signs of pain. A score of two was given when an unhealthy level of oral health was noted. An unhealthy oral health score was defined as bleeding, inflammation, redness, four or more broken or decayed teeth, more than one broken area on dentures, denture not worn, denture missing, food particles/tarter/debris in most areas of the mouth, and/or physical signs of pain as well as verbal or behavioral signs. The following figures represent the percentage of residents in each category who presented with a score of healthy, changes, and unhealthy at the three levels of evaluation. 
Facility A Descriptive Statistics

Figure $1(n=25)$

Figure 1.1

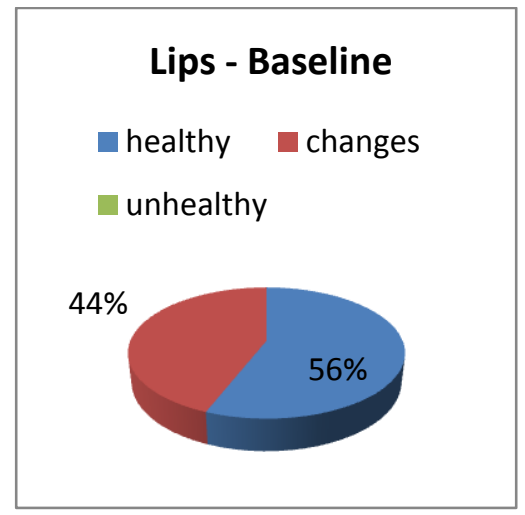

Figure 1.2

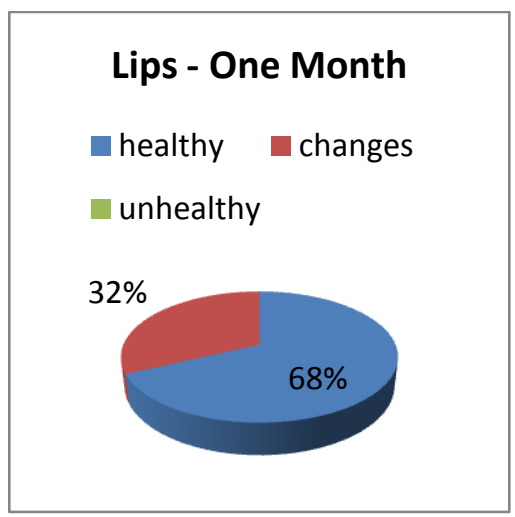

Figure 1.3

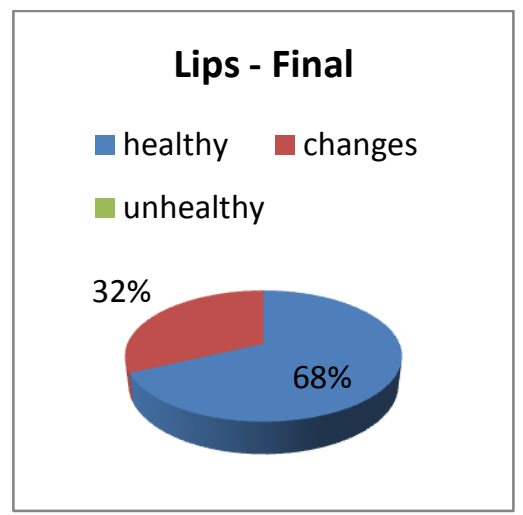

A $12 \%$ improvement in the condition of the lips was noticed from baseline evaluation to one month. Oral health status in this area did not change from one month to final evaluation.

Figure 1.4

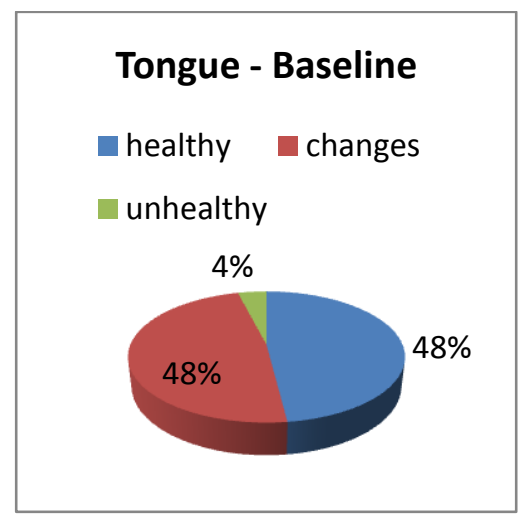

Figure 1.5

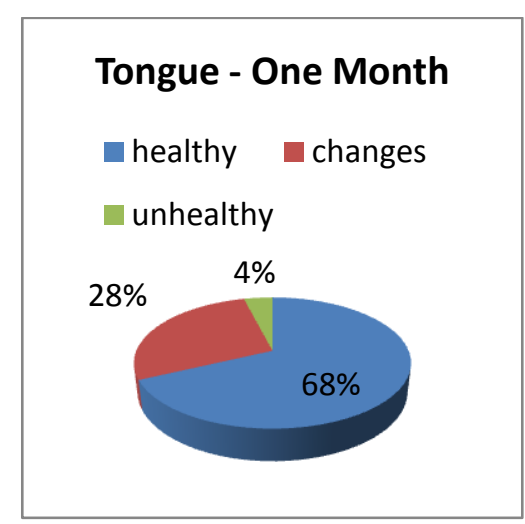

Figure 1.6

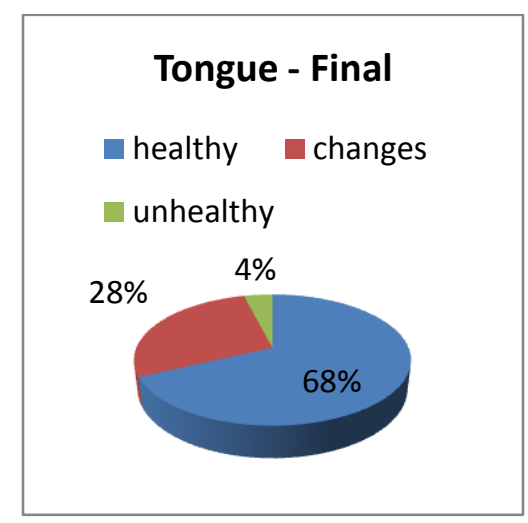

A $20 \%$ improvement in the condition of the tongue was noticed from baseline to one month. Oral health status in this area did not change from one month to final evaluation. 
Figure 1.7

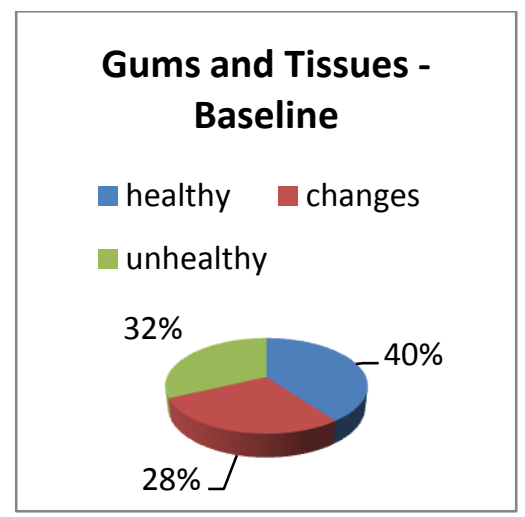

Figure 1.8

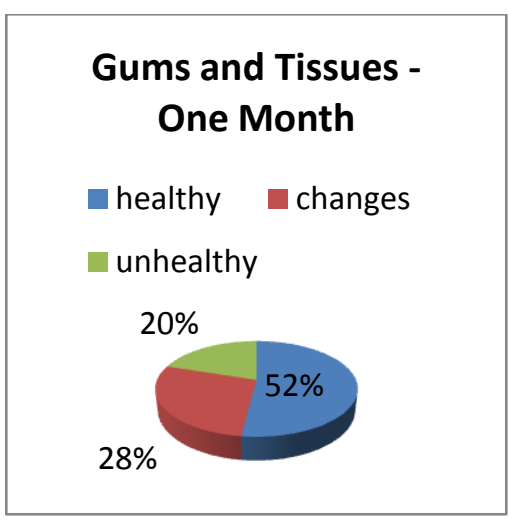

Figure 1.9

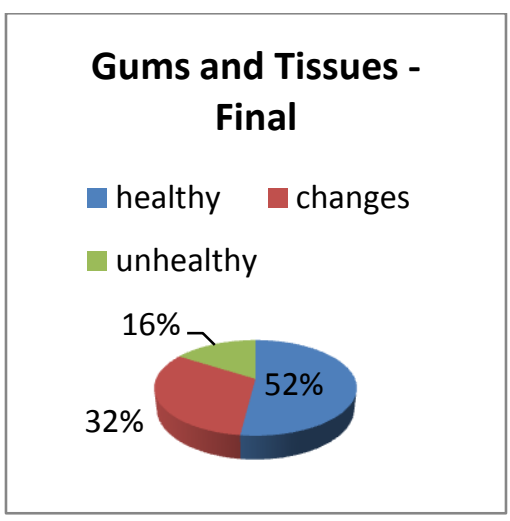

Improvements were noticed in the condition of the gingiva and tissues at all three levels of evaluations.

Figure 1.10

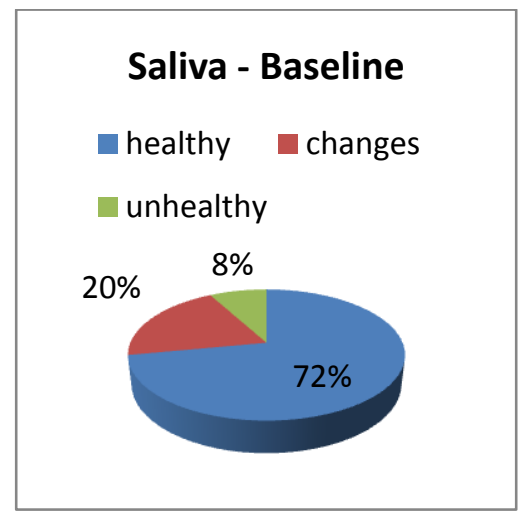

Figure 1.11

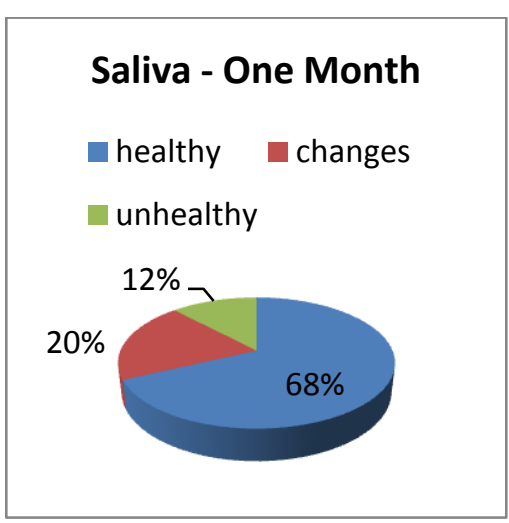

Figure 1.12

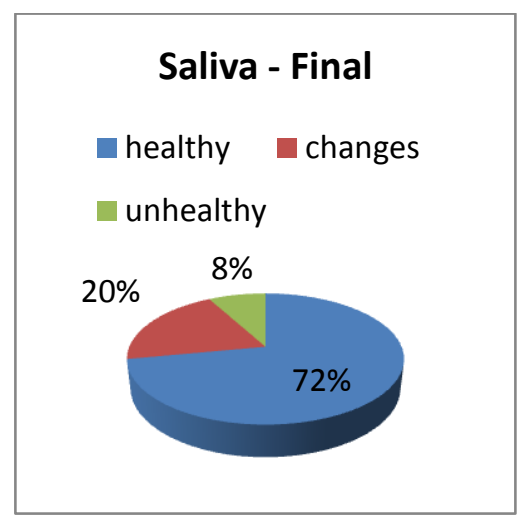

A decrease in the health of the saliva was noted from baseline to one month. At final evaluation the health of the saliva was the same as the baseline evaluation. 
Figure 1.13

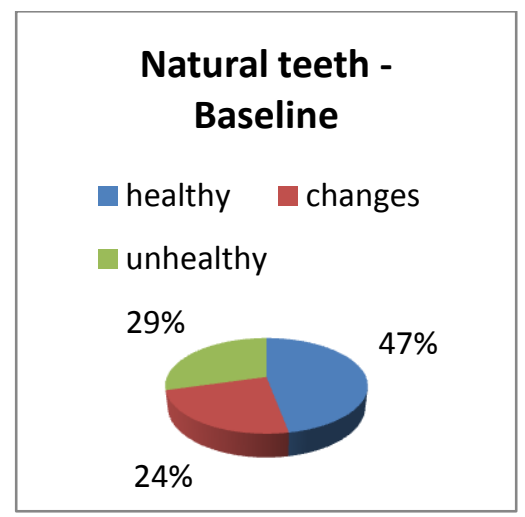

Figure 1.14

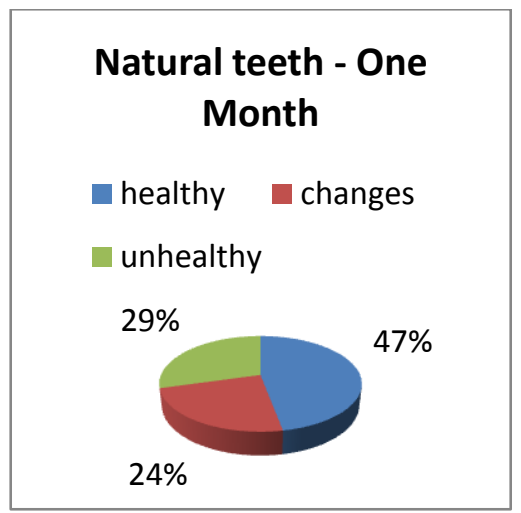

Figure 1.15

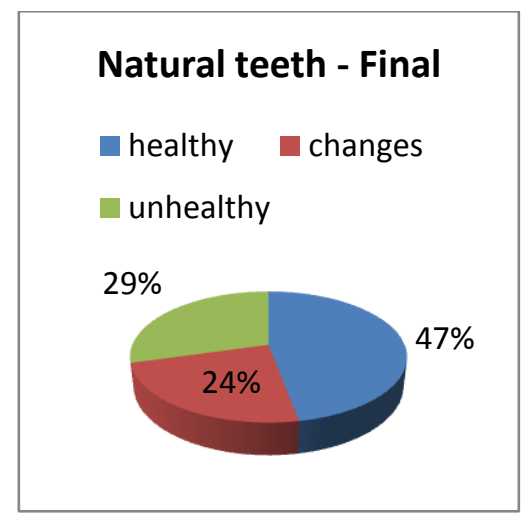

The condition of the natural teeth remained the same throughout the study.

Figure 1.16

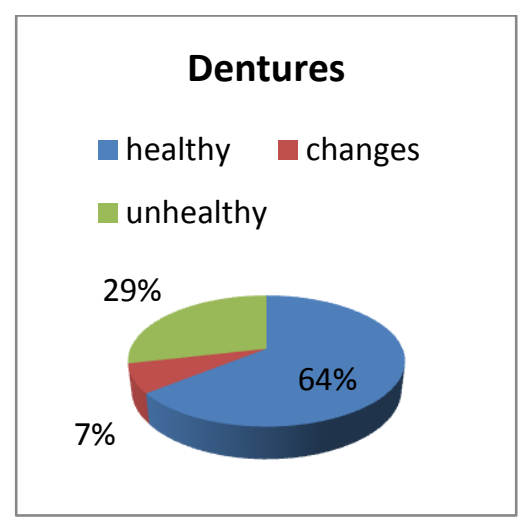

Figure 1.17

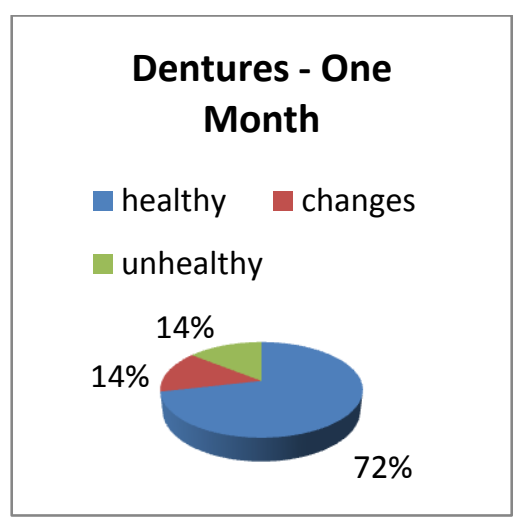

Figure 1.18

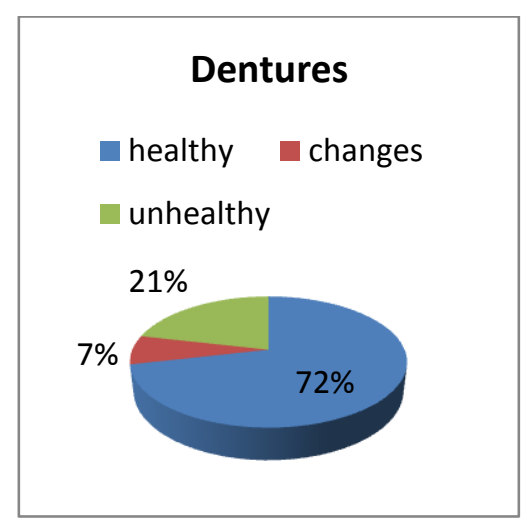

Some improvements were noted in the condition of the dentures from baseline to one month. From one month to final evaluation the percentage of residents with dentures rated as unhealthy increased by $7 \%$. 
Figure 1.19

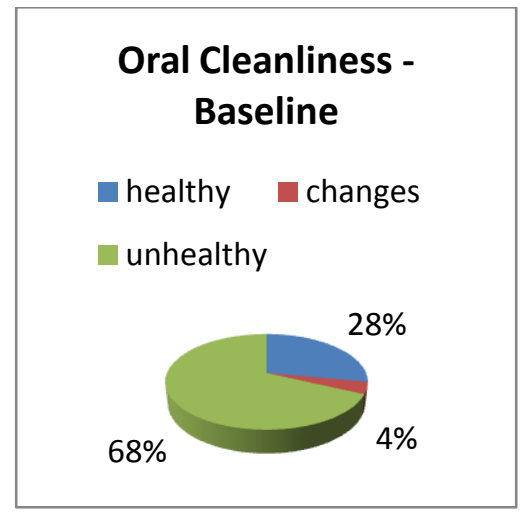

Figure 1.20

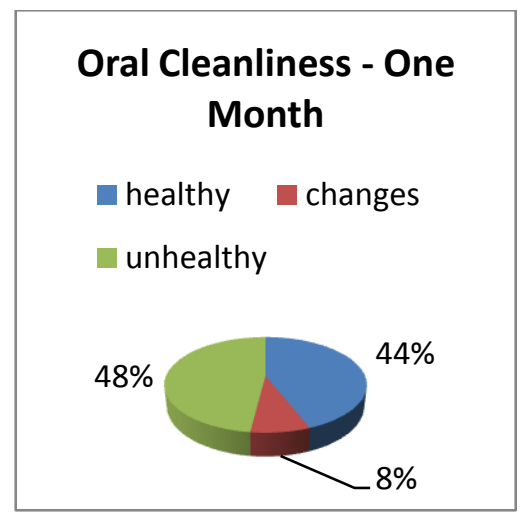

Figure 1.21

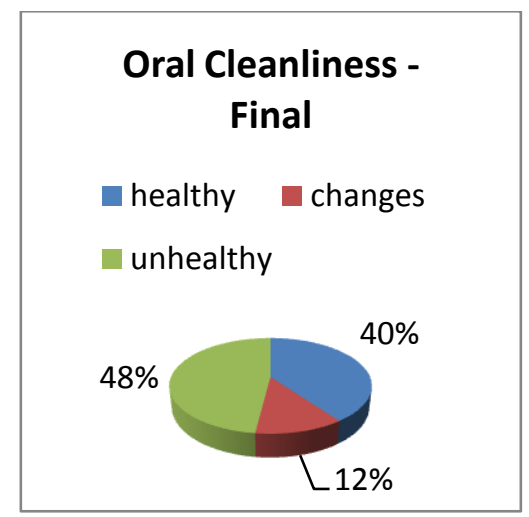

Improvements were noticed in the amount of residents who presented with a healthy level of oral cleanliness from baseline to one month evaluation.

Figure 1.22

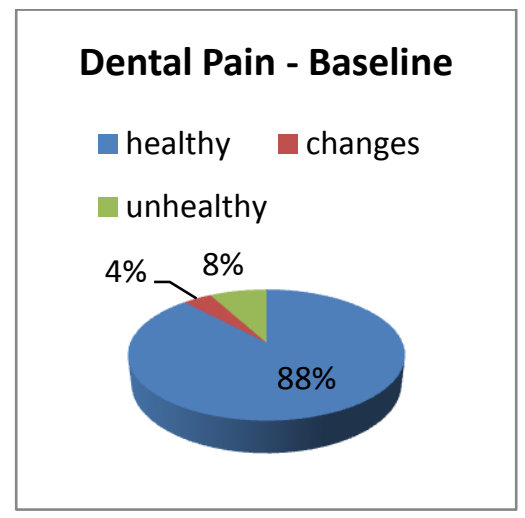

Figure 1.23

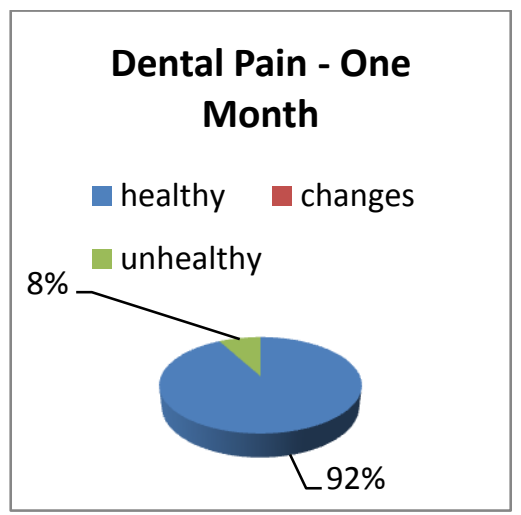

Figure 1.24

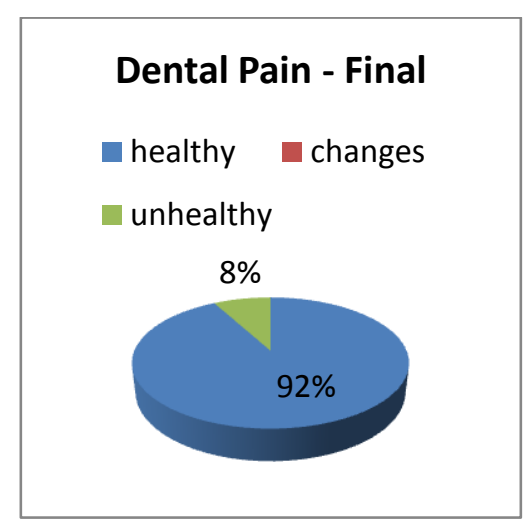

A small percentage of the same residents still presented with an unhealthy level of pain at the completion of the study. 
Facility B Descriptive Statistics

Figure $2(n=26)$

Figure 2.1

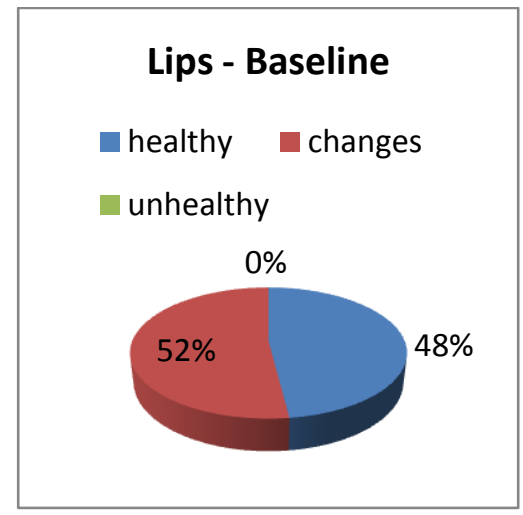

Figure 2.2

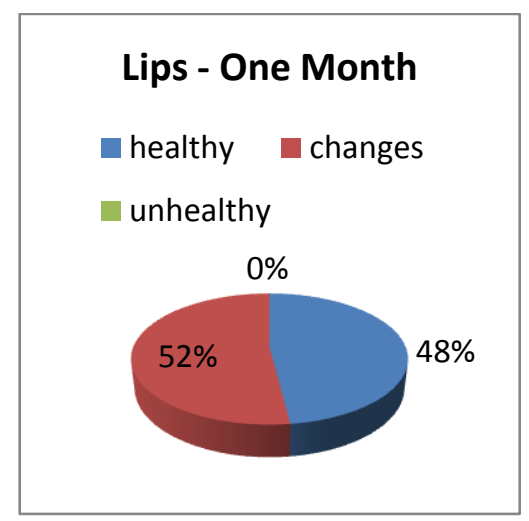

Figure 2.3

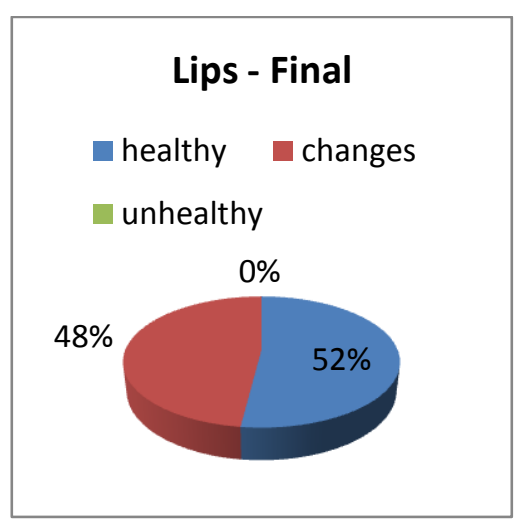

A slight improvement in the condition of the lips was noticed from baseline to final evaluation.

Figure 2.4

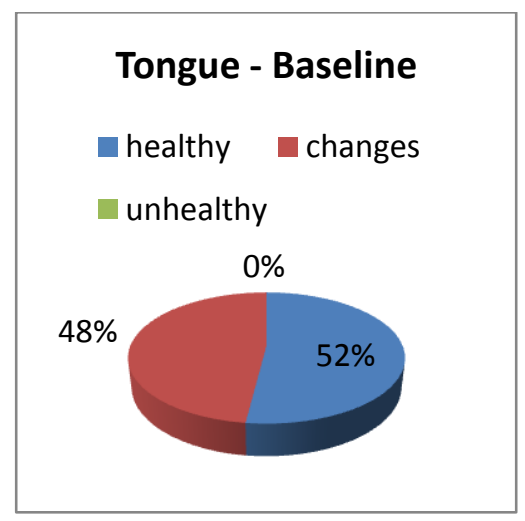

Figure 2.5

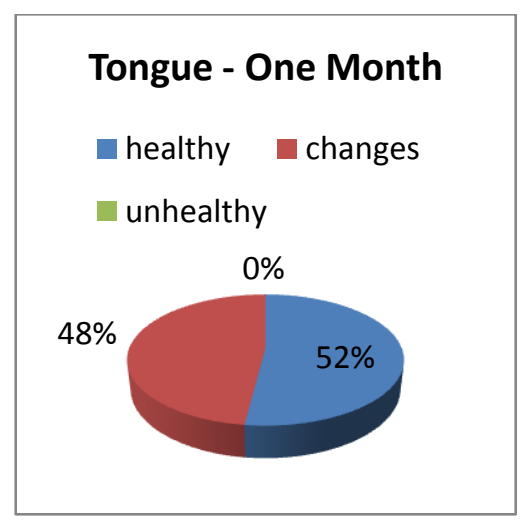

Figure 2.6

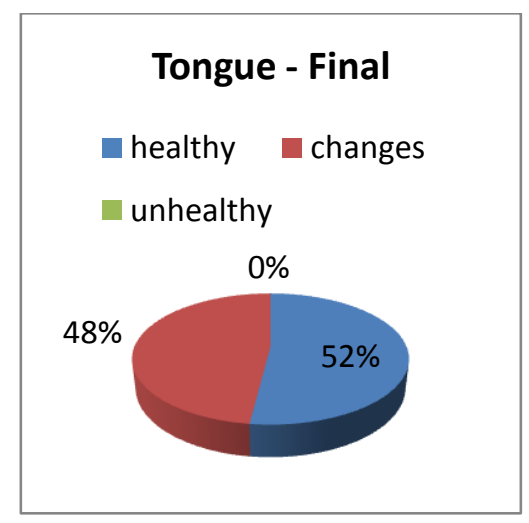

The condition of the tongue remained the same throughout the study. 
Figure 2.7

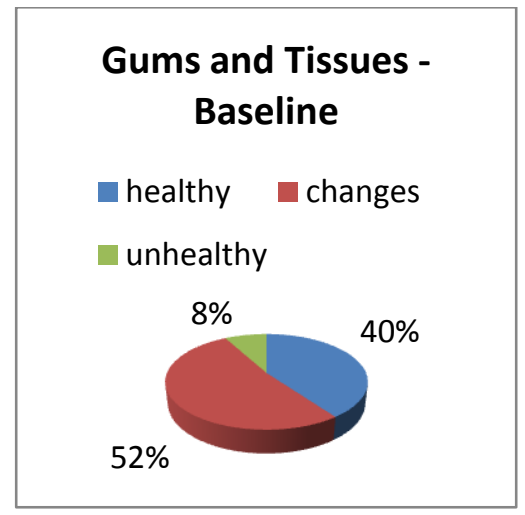

Figure 2.8

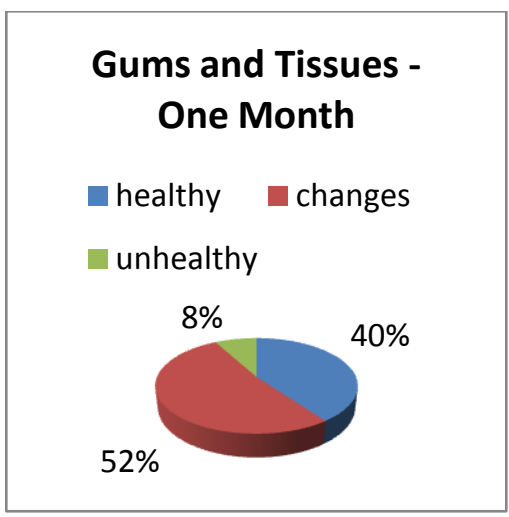

Figure 2.9

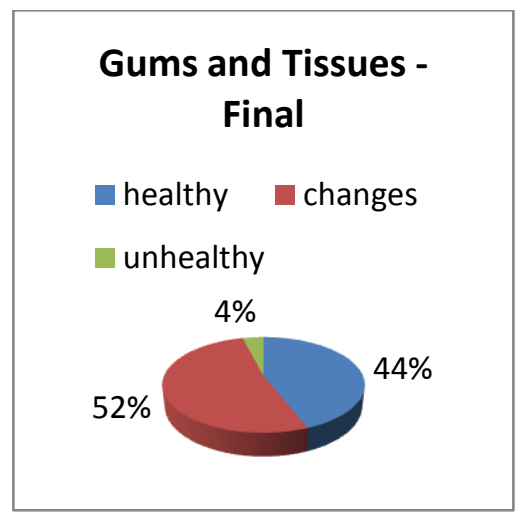

A small percentage of residents showed improvements from an unhealthy status to change in health from baseline to final evaluation.

Figure 2.10

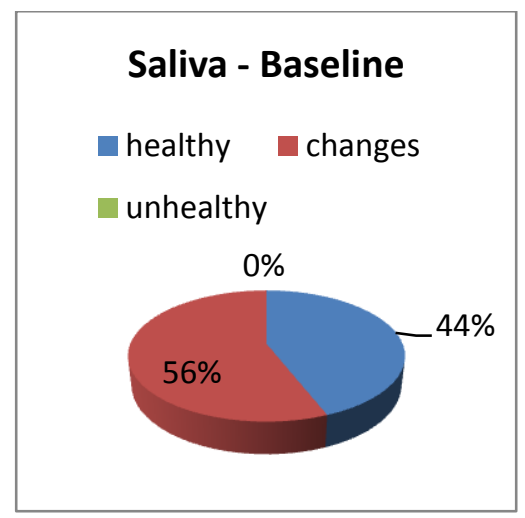

Figure 2.11

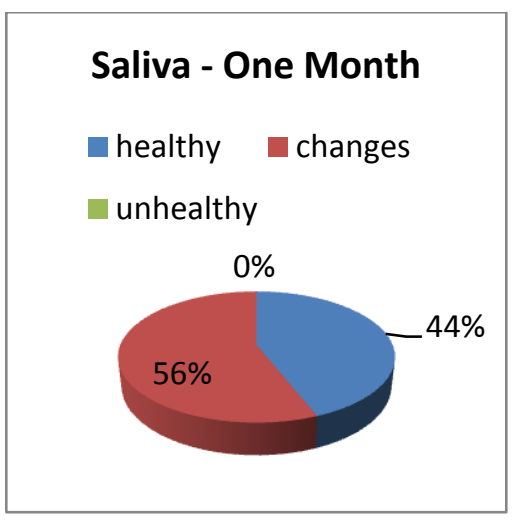

Figure 2.12

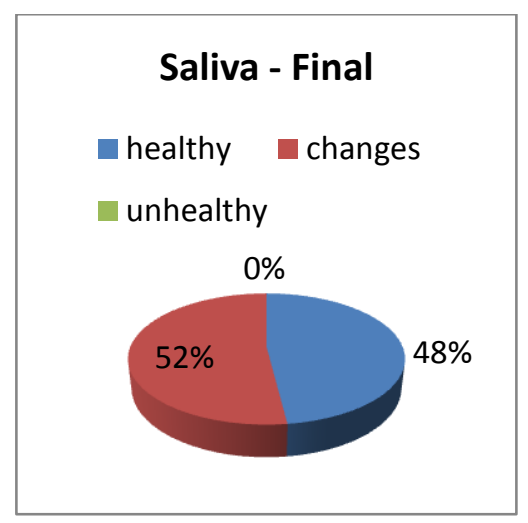

A small percentage of residents presented with improvements to the condition of the saliva at final evaluation 
Figure 2.13

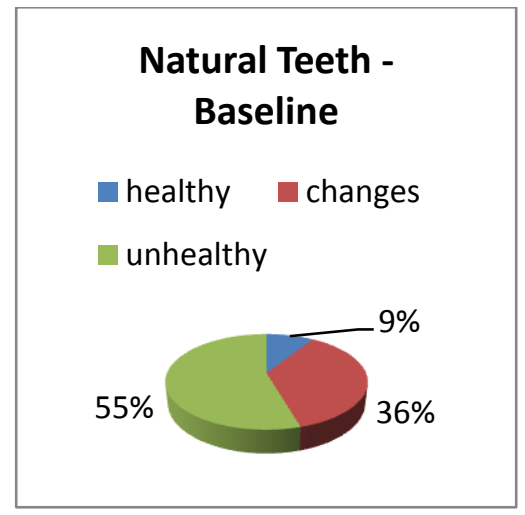

Figure 2.14

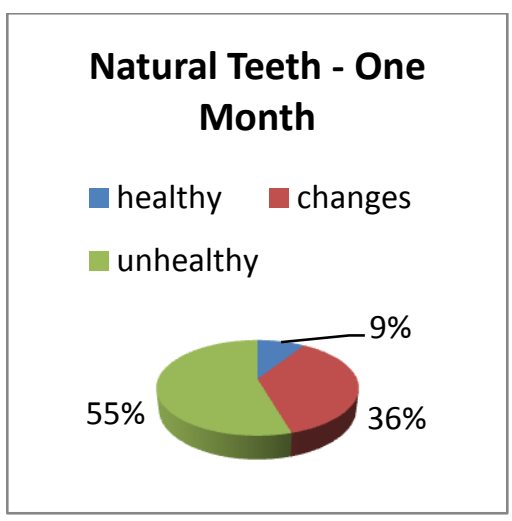

Figure 2.15

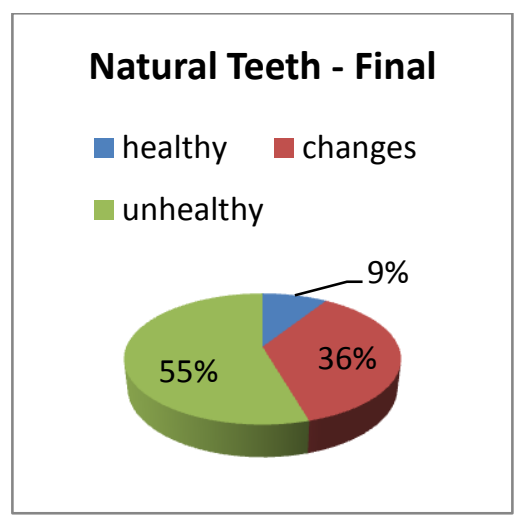

The condition of the natural teeth remained the same throughout the study.

Figure 2.16

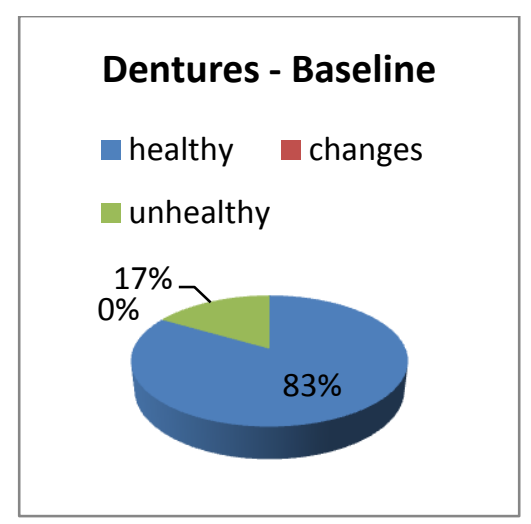

Figure 2.17

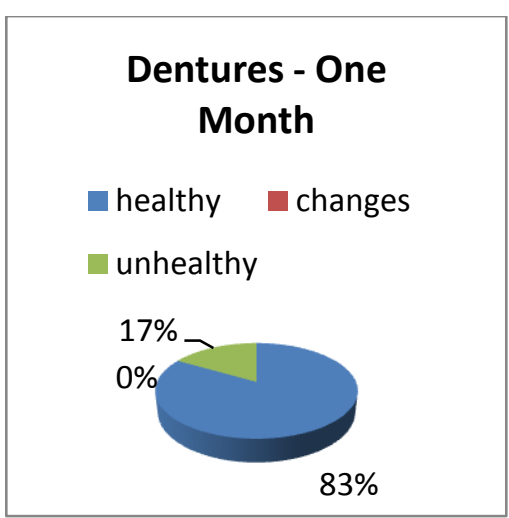

Figure 2.18

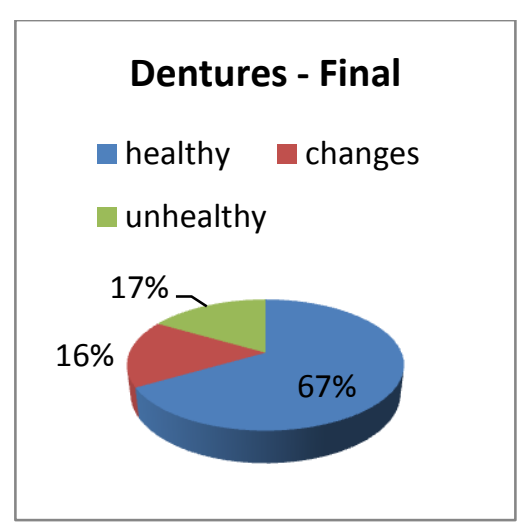

There was a decline in the condition of the dentures by final evaluation. 
Figure 2.19

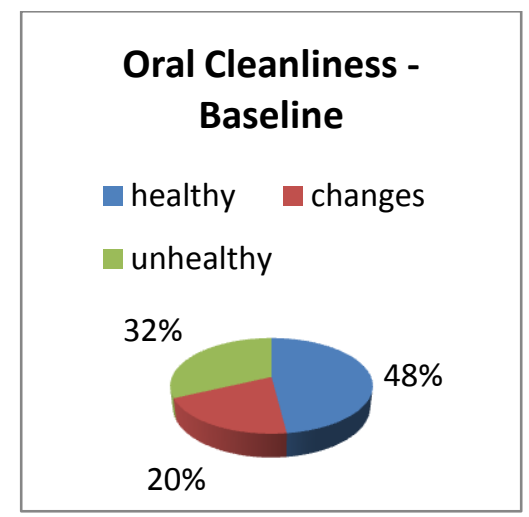

Figure 2.20

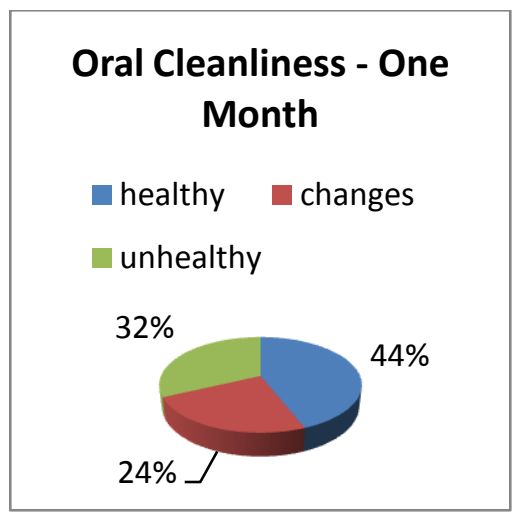

Figure 2.21

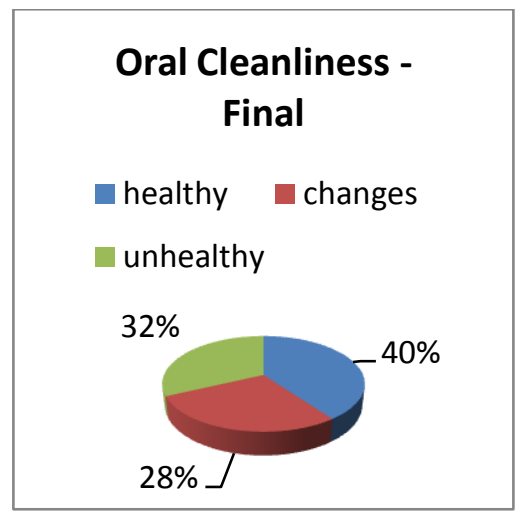

The percentage of residents who presented with a healthy level of oral cleanliness decreased by final evaluation.

Figure 2.22

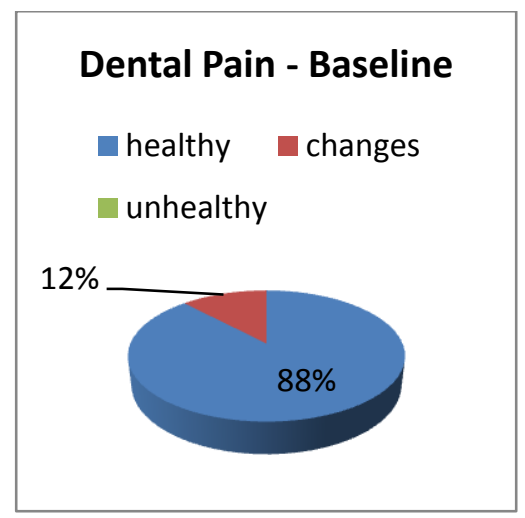

Figure 2.23

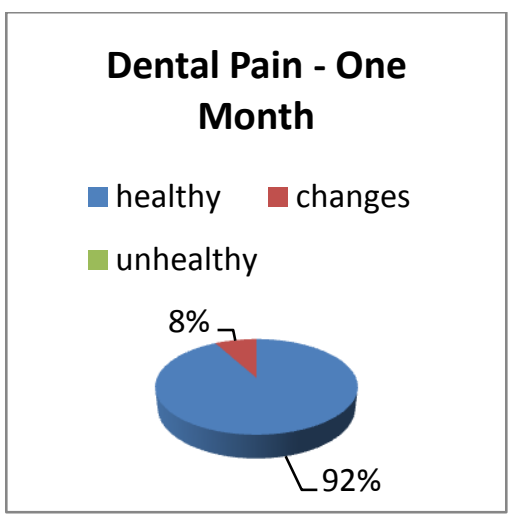

Figure 2.24

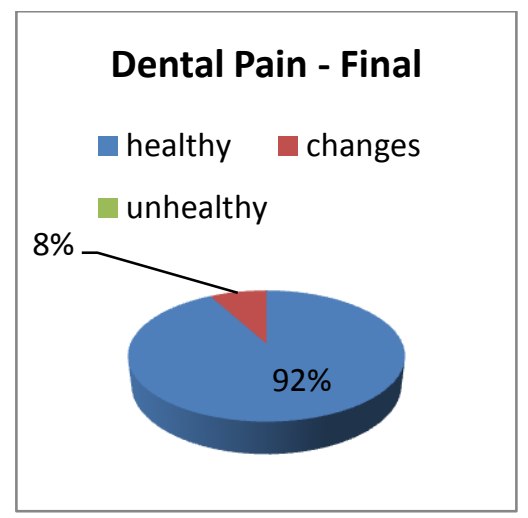

By the completion of the study a low percentage of residents presented with changes in their level of dental pain; however no residents presented with an unhealthy level of dental pain. 


\section{Results of Staff Questionnaires}

Hindrances to providing oral care

Figure $3(n=60)$

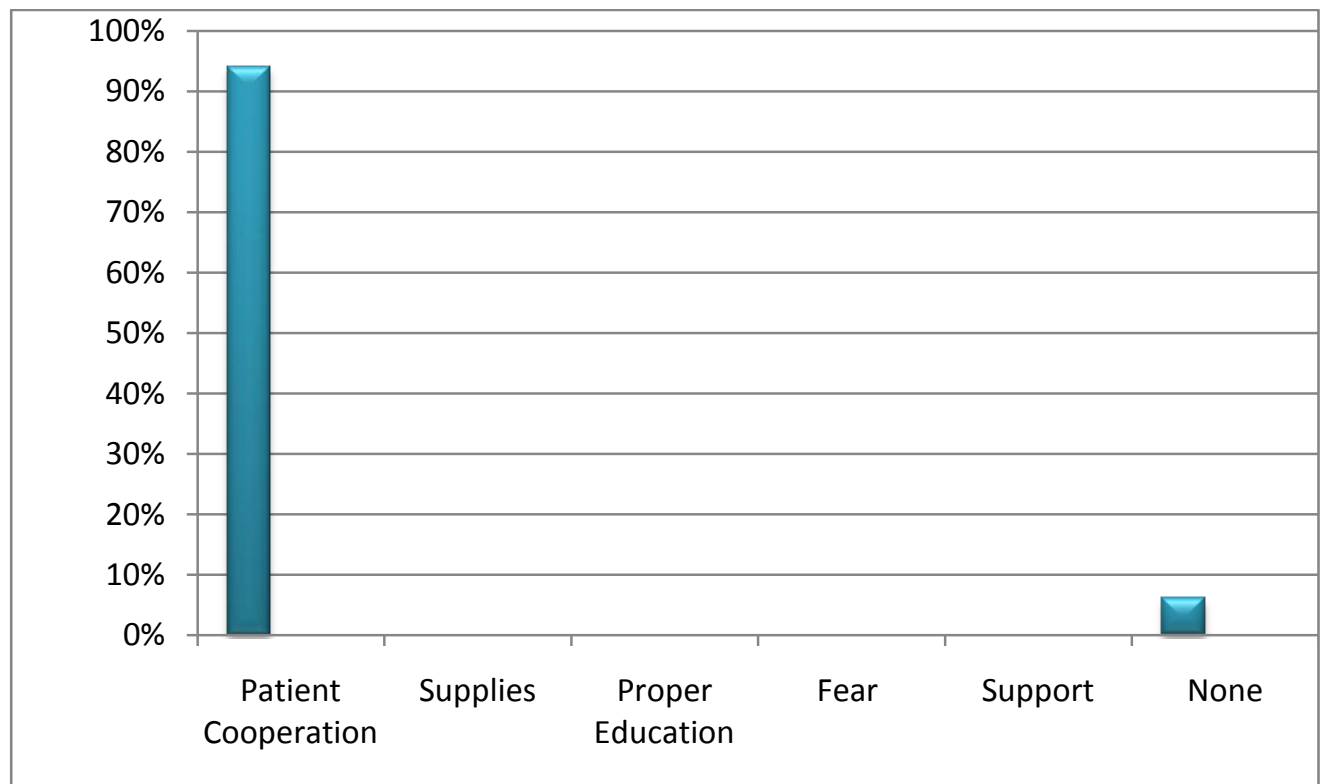

The majority of nursing staff members viewed patient cooperation as the greatest hindrance to providing oral care to the residents. 


\section{Dental Products Used to Provide Oral Care}

Figure $4(n=60)$

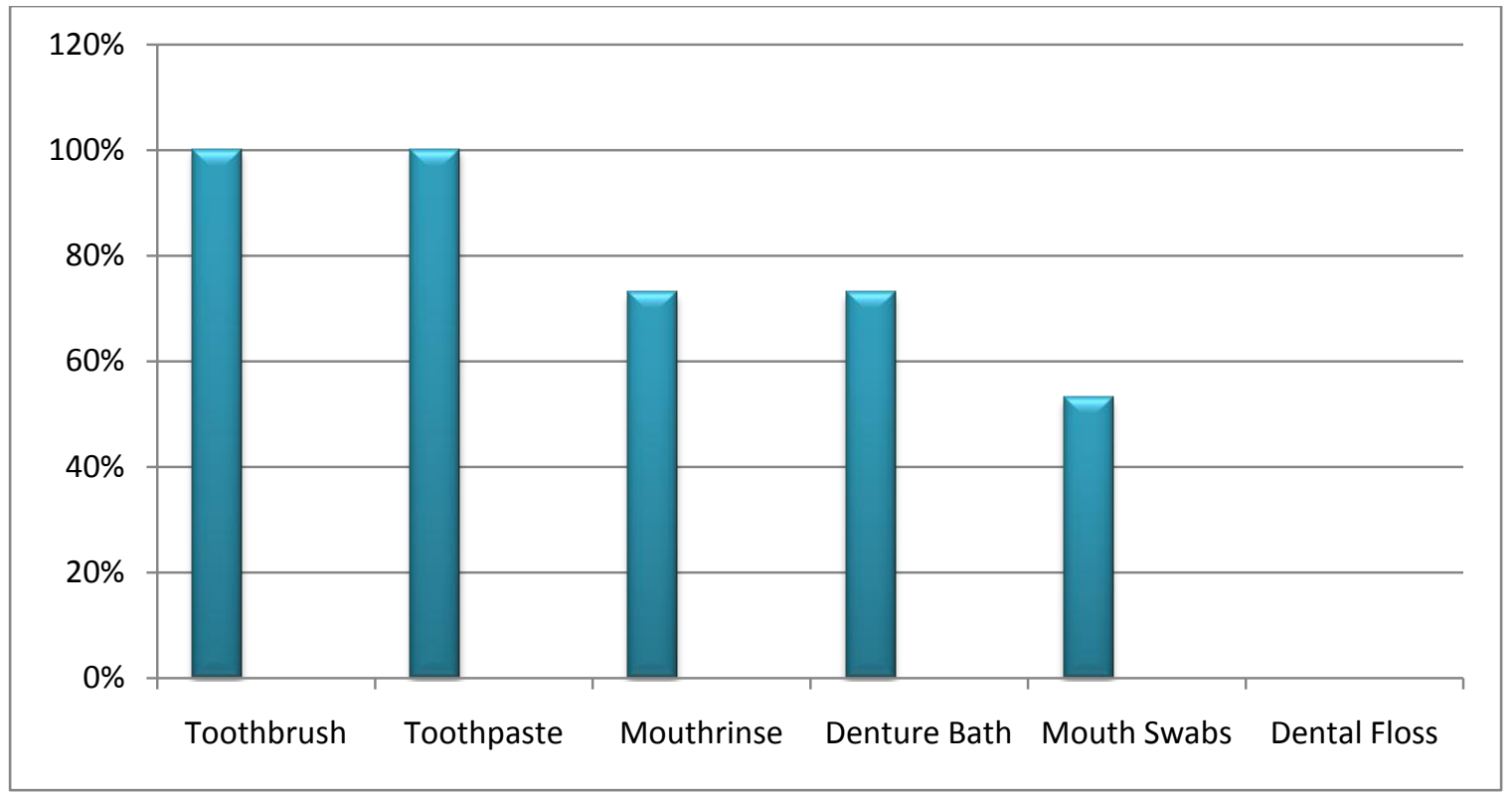

Toothbrushes and toothpaste were used routinely to provide oral care to the residents. Dental floss was never used.

Additional responses to the staff questionnaires included $100 \%$ of those who responded recognized and understood the correlation between oral health and overall well being; 100\% rated their personal attitude toward dental health as very important; $100 \%$ said they received oral health care training when first employed, and $100 \%$ felt having a dental team on staff would have a positive effect of the oral health of the residents. Of those surveyed, $60 \%$ said they would be open to in-service training on oral health care, and $40 \%$ said they would not be interested. 


\section{Questionnaire for Resident/Power of Attorney}

Required Assistance with Oral Care

Figure $5(n=60)$

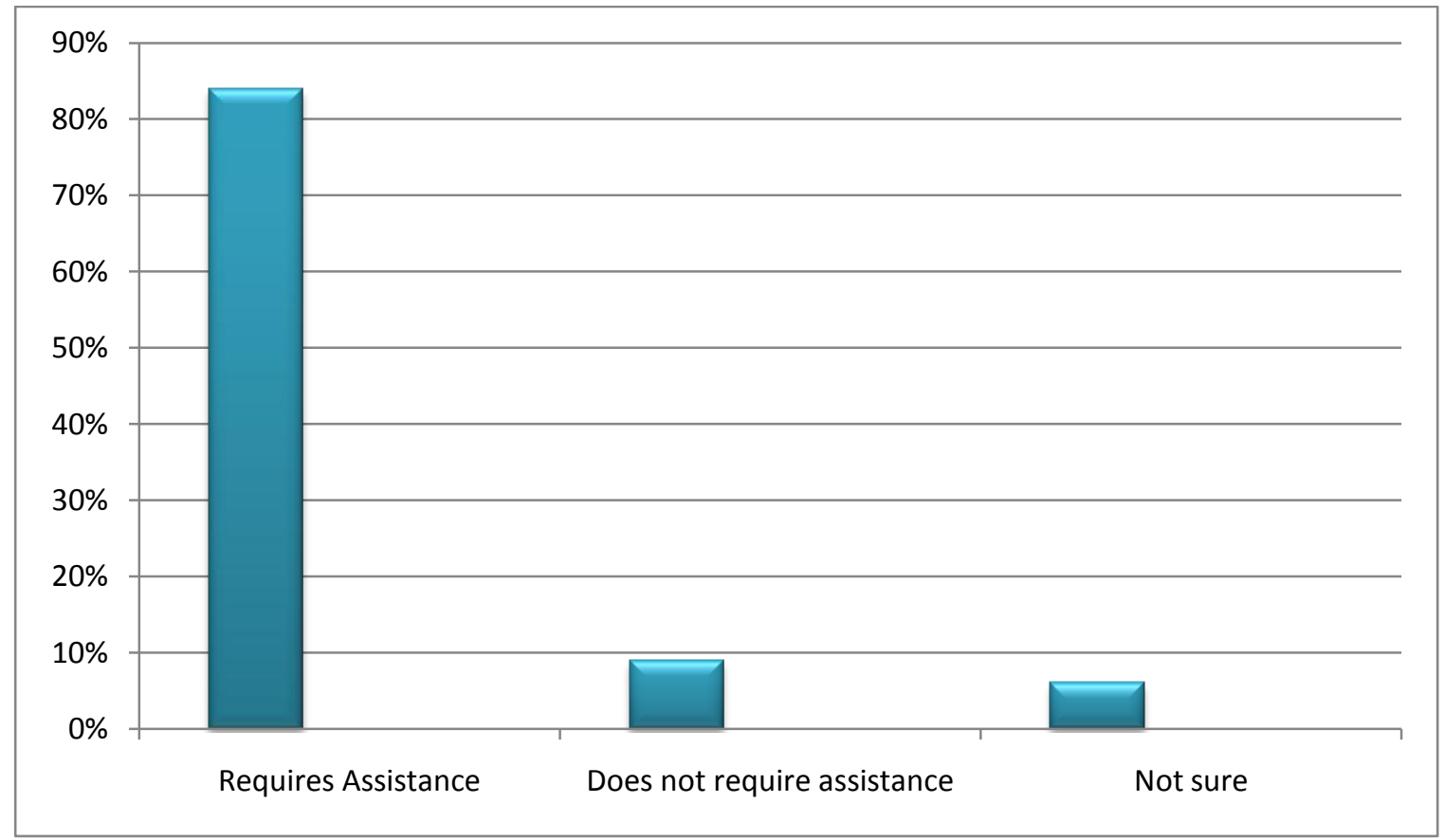

The majority of residents required assistance with their oral care despite their mental health status. 


\section{Perceived Oral Health Rating}

Figure $6(n=60)$

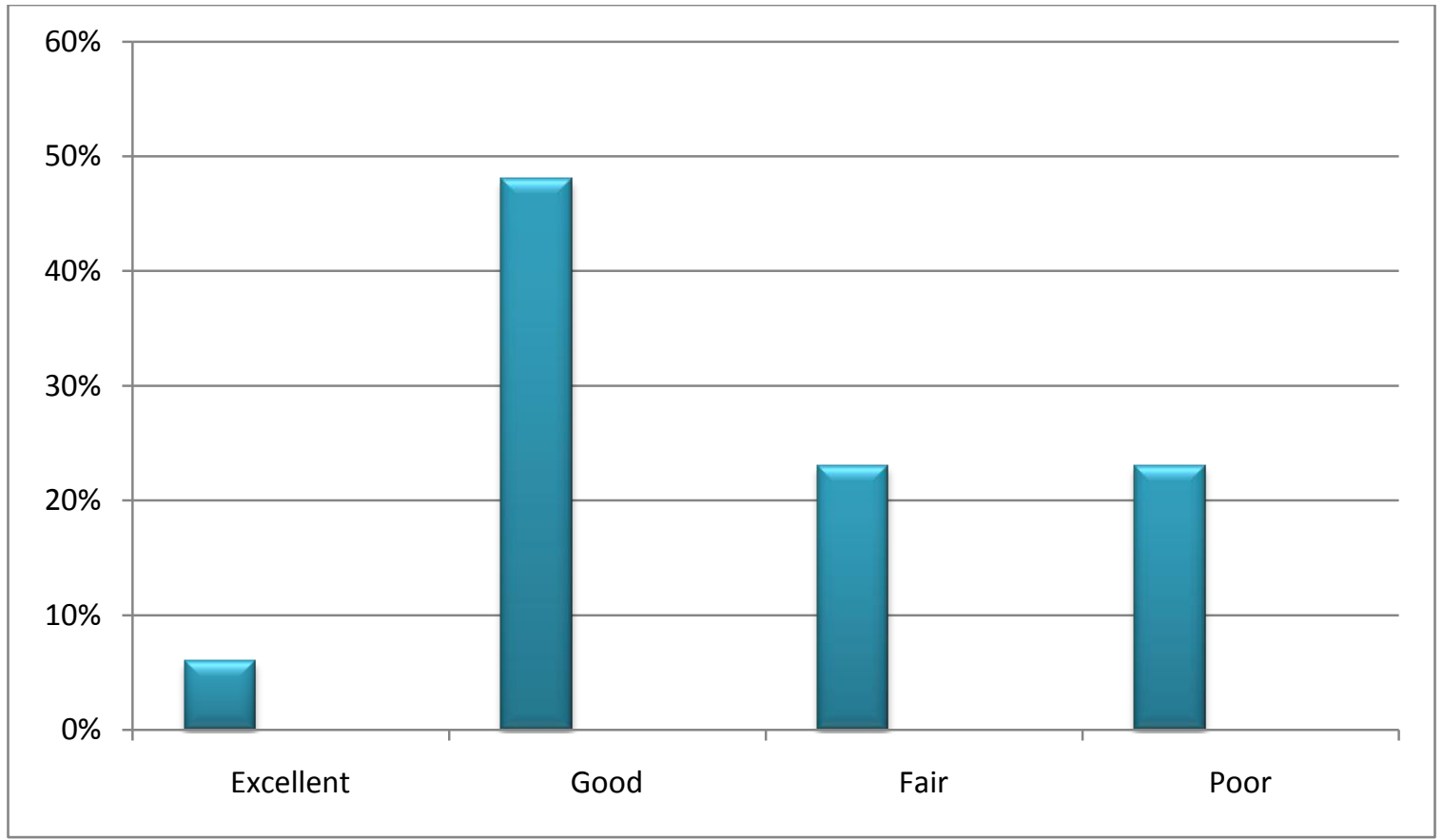

The majority of POA/resident's perceived the oral health status of the resident as good. 
Perception of Having a Dental Team on Staff

Figure $7(n=60)$

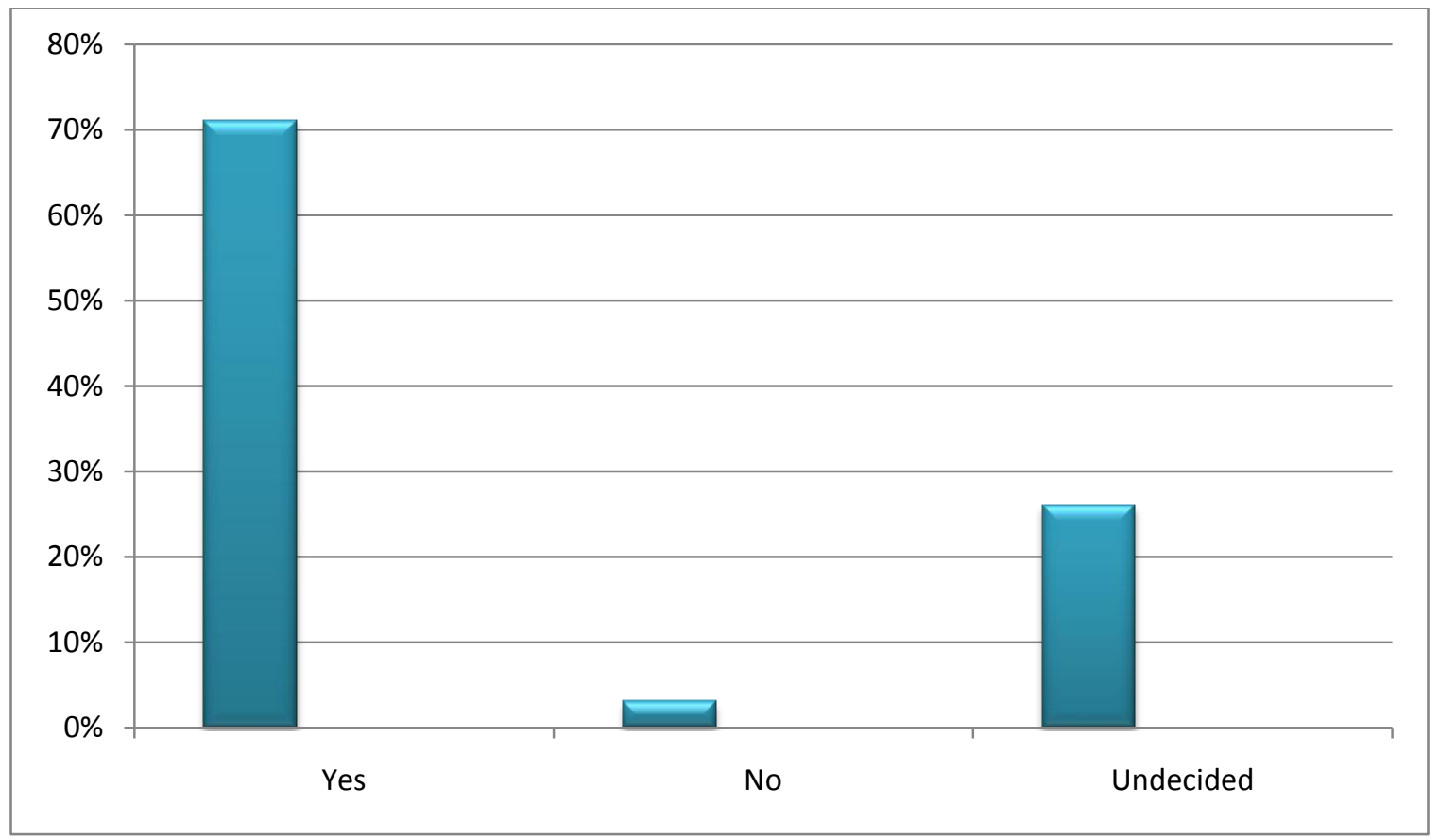

The majority of POA/resident's felt it would be beneficial to have a dental team on staff at the long-term care facility. 


\section{Results of the Factorial ANOVA 2x3}

The researcher looked at two factors (IVs), facility and time of assessment, that influence overall oral health scores (DV). The overall oral health scores were calculated based on the results recorded on the OHAT. A score of 0 was given for healthy findings, a score of 1 was given when changes were noticed, and a score of 2 was given for unhealthy findings. An average oral health score was calculated for each resident at each assessment time. The results were transferred to SPSS for statistical analysis.

\section{STATISTICAL VARIABLES:}

DV = Overall Oral Health Score

$\mathbf{I V}_{\mathbf{1}}=$ Long-term Care Facility (2 Levels=Facility A or Facility B)

$\mathbf{I V}_{\mathbf{2}}=$ Time of Assessment (3 Levels=Baseline, One-Month, or Three-Month)

STATISTICAL TEST: Factorial ANOVA $(2 \times 3)$

\section{RESEARCH QUESTIONS:}

RQ\#1: Is there a statistically significant difference in overall oral health scores among the three times of assessment?

RQ\#2: Is there a statistically significant difference in overall oral health scores between the two long-term care facilities?

RQ\#3: Is there a statistically significant interaction between the time of assessment and the long-term care facility?

\section{NULL \& ALTERNATIVE HYPOTHESES:}

$\mathbf{H}_{0}$ \#1 (Main Effect \#1): There is no statistically significant difference in overall oral health scores among the three times of assessment.

$\mathbf{H}_{\mathbf{a}}$ \#1 (Main Effect \#1): There is a statistically significant difference in overall oral health scores among the three times of assessment.

$\mathbf{H}_{\mathbf{0}}$ \#2 (Main Effect \#2): There is no statistically significant difference in overall oral health scores between the two long-term care facilities.

$\mathbf{H}_{\mathbf{a}}$ \#2 (Main Effect \#2): There is a statistically significant difference in overall oral health scores between the two long-term care facilities. 
$\mathbf{H}_{\mathbf{0}}$ \#3 (Interaction): There is no significant interaction between time of assessment and longterm care facility.

$\mathbf{H}_{\mathbf{a}}$ \#3 (Interaction): There is a significant interaction between time of assessment and longterm care facility.

\section{RESULTS:}

Main Effects: A statistically significant difference in overall oral health scores was not found when comparing the three times of assessment — baseline, one month, and three month - $(\mathrm{df}=2$, $\mathrm{p}=0.628)$ and thus there was failure to reject the first null hypothesis $\left(\mathrm{H}_{0} \# 1\right)$. A statistically significant difference in overall oral health scores was not found when comparing the long-term care facilities - facility A and facility $\mathrm{B}-(\mathrm{df}=1, \mathrm{p}=1.000)$ and thus there was failure to reject the second null hypothesis $\left(\mathrm{H}_{0} \# 2\right)$.

Interaction: A statistically significant interaction between time of assessment and long-term care facility was not found $(\mathrm{df}=2, \mathrm{p}=0.661)$ and thus there was failure to reject the third null hypothesis $\left(\mathrm{H}_{0} \# 3\right)$.

Post-Hoc Comparisons: Post-hoc comparisons among the baseline, one-month, and threemonth times of assessment are not necessary because there were no statistically significant differences found when conducting the omnibus tests.

Figures 8 and 9: Display raw data associated with the overall oral health scores of both facilities. 
Figure 8

\section{Tests of Between-Subjects Effects}

Dependent Variable:Overall Oral Health Score

\begin{tabular}{|l|r|r|r|r|r|}
\hline Source & $\begin{array}{c}\text { Type III Sum } \\
\text { of Squares }\end{array}$ & df & Mean Square & \multicolumn{1}{c|}{ F } & \multicolumn{1}{c|}{ Sig. } \\
\hline Corrected Model & $.362^{\mathrm{a}}$ & 5 & .072 & .346 & .884 \\
Intercept & 50.342 & 1 & 50.342 & 240.777 & .000 \\
TimeOfAssessment & .195 & 2 & .098 & .467 & .628 \\
Facility & $9.050 \mathrm{E}-9$ & 1 & $9.050 \mathrm{E}-9$ & .000 & 1.000 \\
TimeOfAssessment ${ }^{*}$ & .173 & 2 & .087 & .415 & .661 \\
Facility & 30.735 & 147 & .209 & & \\
Error & 81.458 & 153 & & & \\
Total & 31.097 & 152 & & & \\
Corrected Total & & & & \\
\hline
\end{tabular}

a. R Squared $=.012$ (Adjusted R Squared $=-.022$ )

Figure 9

\section{Descriptive Statistics}

Dependent Variable:Overall Oral Health Score

\begin{tabular}{|cc|c|r|r|}
\hline Time of Assessment & Long-Term Care Facility & Mean & Std. Deviation & N \\
\hline Baseline & Facility A & .6716 & .45040 & 25 \\
& Facility B & .5765 & .46040 & 26 \\
& Total & .6231 & .45350 & 51 \\
\hline One-Month & Facility A & .5184 & .46755 & 25 \\
& Facility B & .5712 & .45959 & 26 \\
& Total & .5453 & .45962 & 51 \\
\hline Three-Month & Facility A & .5312 & .45923 & 25 \\
& Facility B & .5735 & .44626 & 26 \\
& Total & .5527 & .44862 & 51 \\
\hline Total & Facility A & .5737 & .45822 & 75 \\
& Facility B & .5737 & .44952 & 78 \\
& Total & .5737 & .45231 & 153 \\
\hline
\end{tabular}


Figure 10

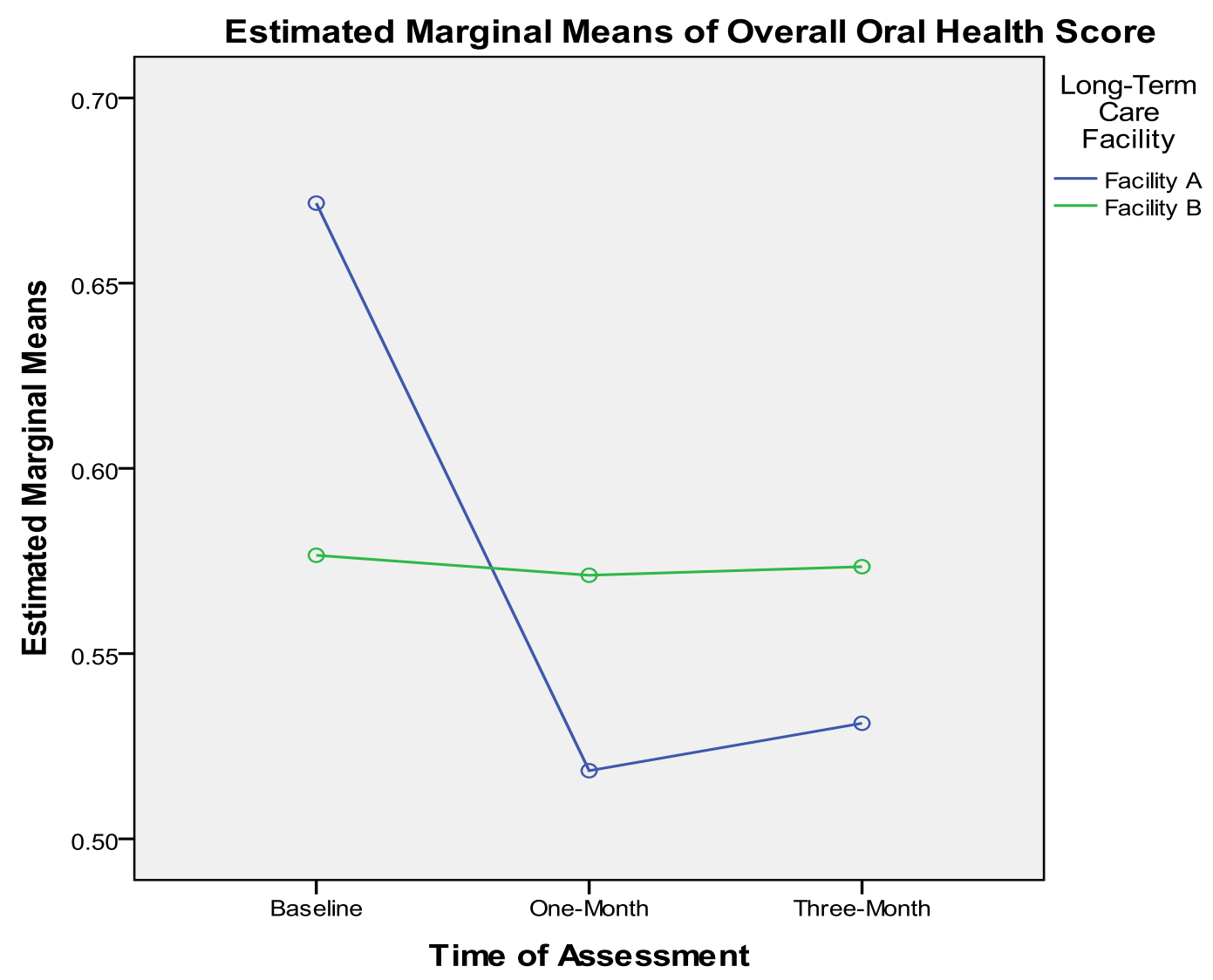

Although the results were not statistically significant, the overall oral health scores of the residents in Facility A improved between baseline and one month following oral health interventions by the dental team. At the onset of this study, residents in Facility A demonstrated oral health scores lower than those of residents residing in Facility B. Although a slight rise in oral health scores is noted between one month and three month intervals in Facility A, the oral health scores of those residing in Facility A were better than those residing in Facility B at the completion of the study. 


\section{DISCUSSION}

Interpretation of the results will begin with discussion on the ANOVA statistical test. Three areas were compared during the ANOVA. The first main effect was to determine if there was a statistically significant difference in the overall oral health scores among the three times of assessment. The second main effect was to determine if there was a statistically significant difference in overall oral health scores between the two facilities. The interaction was to determine if there was a statistically significant difference between the time of assessment and the long-term care facility. Results showed no statistical significance at any level, with $\mathrm{p}=.628$, 1.0, and .661 respectively (Figure 8). Therefore it could be concluded there is no difference in oral health scores based on the time of assessment, the facility, or both when comparing a facility which has a dental team and protocol versus a facility that does not have a dental team and protocol. Comparisons based on the time of assessment also conclude there is no statistical difference in the oral health scores of the residents following the dental in-services program presented to the staff at both facilities.

Although the chosen statistical test does not show any significance in the results, descriptive statistics reveal some interesting findings that could warrant further investigations. Facility A showed improvements in most categories between baseline and one month evaluations (Figures 1.1-1.24). The conditions of the lips improved by $12 \%$ after recommendations were given to lubricate the lips to prevent further cracking. The health of the tongue showed a $20 \%$ improvement after recommendations were given to brush the patients' tongues daily. The health of the gingiva and tissues showed at $12 \%$ improvement and the level of oral cleanliness improved, following oral care instruction and dental cleanings. A smaller percentage of residents presented with unhealthy dentures at the one month evaluation. The improvements can 
be contributed to repairs and relines of the patients' dentures. There were no improvements in the condition of the saliva which could be attributed to the fact that no alterations were made in medications and no saliva substitutes were prescribed. There were also no changes noticed in the condition of the natural teeth, and a small percentage of residents presented with dental pain. Recommendations were given for restorations and extractions which were declined by the resident or POA. Figure 10 shows a significant decrease in the overall oral health scores of the residents between the baseline and one month interval. The oral health scores generally remained the same between the one month and final evaluations. The investigator speculates, through the interpretation of the descriptive statistics, the implementation of the dental team able to provide restorative treatment could have a positive effect on the oral health of the residents living in long-term care facilities even if the effects are not statistically significant. Current research supports the need for dental professionals working collaboratively with the nursing staff and family members/POA in long-term care to improve the oral health of the residents.

Descriptive statistics did not reveal as much improvement for Facility B (Figures 2.12.24). The overall oral health scores for each resident evaluated generally remained the same throughout the entire study. When slight improvements were noticed, there was no consistency between which intervals of the examinations the changes were found. The investigator speculates education alone provided to the care staff, is not enough to improve the oral health of residents living in long-term care facilities.

Results of the staff questionnaires revealed patient cooperation as the only hindrance to providing oral care. During the in-service training at Facility B, the staff commented inadequate supplies were also an issue. The staff commented that the toothbrushes fell apart easily, the tooth paste was inadequate, and denture brushes were not available. The researcher provided this 
information to the administrator and requests for suitable supplies were submitted for the facility. Nearly half the staff polled was not interested in attending in-service training, however $100 \%$ felt having a dental team on staff would have a positive effects on the oral health of the residents. The researcher concluded that the nursing staff would welcome a dental team to the facility and would prefer that the dental team be responsible for the oral health of the residents.

Resident/POA questionnaires revealed the majority perceived the oral health of the residents as being good. Over $70 \%$ polled had a positive perception of having a dental team on staff. The researcher spoke with a resident who said he had been to several facilities in the past 15 years and the researcher was the first dental professional he had ever seen in any of the facilities. He verbally expressed that he would be "thrilled" to have a dental team on staff.

\section{SUMMARY AND CONCLUSIONS}

Based on the data collected, literature reviewed, and the investigator's experience, the following can be concluded:

1. The oral health scores of the residents in Facility A showed some improvements (particularly from baseline to one month) in most areas following oral health interventions from the dental team.

2. Having a dental team and an oral health protocol can have a positive effect on the oral health of the residents living in long-term care facilities even if the effects are not statistically significant.

3. A dental hygienist with a general supervision and public health permits has an important role at long-term care facilities. 
4. The oral health scores of the residents in the facility without the dental team remained fairly consistent throughout the study.

5. Proper education alone provided to long-term care staff is not enough to improve the oral health status of residents living in long-term care.

6. Despite OBRA law, oral health interventions at baseline in both facilities investigated were negligible.

7. For the most part facilities do not perform oral care adequately and unless you have a team authorized to perform oral care, little to no improvements will result.

\section{RECOMMENDATIONS FOR THIS STUDY}

Based on the descriptive statistics from facility A, the condition of the natural teeth remained the same throughout the study, therefore recommendations in this category were not followed. Rejection of services by the resident or POA ranged from cost to not wanting to put the patient through the treatment. Recommendations by the dental team for improving oral health were implemented to some extent, as can be seen from the decrease in scores between baseline and one month evaluations (Figure 10). Therefore, perhaps dental hygienists with general supervision and public health permits have an important role in long-term care facilities. Providing proper daily oral care could improve the oral health of the residents which in turn could improve the overall health and well-being of the residents. The families and/or POA's of the residents need to be included in the educational component of the oral care process so they have the information necessary to make appropriate decisions.

Another interesting observation was noted. A particular resident living in Facility A was examined at all three intervals. She suffered a stroke several years ago and had been living in the 
facility from the time of her stroke. She was physically and cognitively impaired, relying on the staff to meet all her needs. The patient was on several medications and presented with xerostomia. The patient's husband dedicated himself to providing his wife with daily oral care. For the past several years he brushed and flossed her teeth daily. The patient received a score of 0 (healthy) at all levels of examination. The condition of her oral health was remarkable. The patient went on to have a dental cleaning at the facility. Not all patients are fortunate to have family members who would dedicate their time to ensuring their loved one receives proper daily oral care. This particular patient's daughter happens to be a dental hygienist. The findings of this patient lead the investigator to conclude a dental hygienist with general supervision and public health permits has a much needed role in long-term care facilities. The continuing education component of these permits should focus on geriatrics.

The investigator believes it is important to have multiple dental hygienists on staff at long-term care facilities. The responsibility of the hygienists would be to provide daily oral care to the residents. Incorporating dental hygienists could make great improvements to the oral health status of the population of people living in long-term care.

For this study, because improvements were noticed in the oral health scores of the residents in Facility A based on descriptive statistics (Figures 1.1-1.24) and the sharp decrease noticed in Figure 10 from baseline to one month, the researcher suggests a larger population of residents should be assessed. Results of the ANOVA were not statistically significant; however, having a larger population of residents may have yielded significant results. Future studies should include a larger population of residents. 


\section{RECOMMENDATIONS FOR FUTURE STUDIES}

A future study should be conducted at Facility A to determine if the improvements in the oral health of the residents were sustained over time. Facility B is now pursuing having a dental team join their staff.

Another study should be conducted, after the facility implements the dental team, to see if improvements are made based on this study's findings.

A future study could be done to determine if the spin brushes helped to improve the oral health of the residents. Both facilities are discussing the purchasing of spin brushes for residents to receive upon admission to the facility.

Lastly, a national study could be done to determine the compliance of OBRA law in longterm care facilities. 


\section{REFERENCES}

1. Coleman, P., \& Watson, N.M. (2006). Oral care provided by certified nursing assistants in nursing homes. The American Geriatrics Society, 54, 138-143.

2. Moser, M., Nathe, C., \& Pino, A. (2003). Status of oral health care in long-term care facilities. International Journal of Dental Hygiene, 1, 169-173.

3. Ede-Nichols, P.E., Gargia-Godoy, F., \& Murray, P.E. (2006). Oral health in Florida nursing homes. International Journal of Dental Hygiene, 4, 198-203.

4. Chalmers, J., \& Pearson, A. (2005). Oral hygiene care for residents with dementia: a literature review. Journal of Advanced Nursing, 52(4), 410-419.

5. The importance of oral health in long-term care. Journal of the American Medical Directors Association 2009; 10(9), 667-671.

6. Andersson, P., Rejnefelt, I., \& Renvert, S. (2005). Oral health status in individuals with dementia living in special facilities. International Journal of Dental Hygiene, 4, 67-71.

7. Oral health and the aging population. Journal of the American Dental Association 2007; $138,55-65$.

8. Geriatric oral health and pneumonia risk. Journal of Infectious Diseases2005; 40(12), 1807-1810.

9. Hanada, N., Tada, A., Tanzawa, H., Watanabe, T., \& Yokoe, H. (2002). Oral bacteria influenced by the functional status of elderly people and the type and quality of facilities for the bedridden. The Society for Applied Microbiology, 93, 487-491.

10. Provisions of mouthcare in long-term care facilities: an educational trial. Community Dentistry and Oral Epidemiology 2007; 35(1), 25-34.

11. Oral health coordinators in long-term care-a pilot study. Special Care Dentistry 2010; $30(2)$, 59-65.

12. Andersson, L., Berggren, U., Hallber, L., Sorensen, St., \& Wardh, I. (2000). Oral health 
care-a low priority in nursing. Scandinavian Journal of Caring Sciences, ISSN 02839318, 137-142.

13. Frenkel, H., Harvey, I., \& Needs, K. (2002). Oral health care education and its effect on caregivers' knowledge and attitudes: a randomized controlled trial. Community Dentistry and Oral Epidemiology, ISSN 0301-5661, 91-99.

14. Sorensen, S., Wardh, I., \& Wikstrom, M. (2004). Oral bacteria and clinical variables in dependent at a special facility. International Journal of Dental Hygiene, 2, 185-192.

15. Bagg, J., McHugh, S., Nicol, R., \& Sweeney, P. (2004). Effectiveness of health care worker training on the oral health of elderly residents of nursing homes. Community Dentistry and Oral Epidemiology, 33, 115-124.

16. Andersson et al. (2003). Oral health education for nursing personnel; experiences among specially trained oral care aides: one year follow-up interviews with oral care aides at a nursing facility. Scandinavian Journal of Caring Sciences, 17, 250-256.

17. Cheruvu, V.K., Mahalaha, S.A., \& Smyth, K.A. (2009). Oral cancer screening: practices, knowledge, and opinions of dentists working in Ohio nursing homes. Special Care Dentistry, 29(6), 237-243.

18. Leslie, L., \& Girts, K. (2004). Maintaining oral health in the nursing facility. Nursing Homes Long Term Care Management, 62-63.

19. Carter, K.D., Chalmer, J.M., King, P.L., Spencer, A.J., \& Wright, F.A.C. (2005). The oral health assessment tool - validity and reliability. Australian Dental Journal, 50 (3), 191-199.

20. http://www.wikipedia.org

21. http://apps.sos.wv.gov/adlaw/files/rulespdf/64-13.pdf. West Virginia Office of Health Facility Licensure and Certification. 


\section{APPENDIX A}

\section{INSTITUTIONAL REVIEW BOARD APPROVAL FOR THE}

PROTECTION OF HUMAN SUBJECTS 


\section{W-WestVirginiaUniversity. \\ Office of Research Compliance}

IRB Protocol Expedited IAA Acceptance

To:

From: WVU Office of Research Compliance

Date: $\quad$ Monday, September 20, 2010

Subject: No action required

Tracking \#: H-22676

Title: $\quad$ The Effects on the Oral Health Care of Residents Living in Long Term

Care Facilities with the Implementation of a Dental Protocol and Team

The West Virginia University Institutional Review Board (IRB) Executive Committee reviewed and approved your request for an Institutional Review Board Authorization Agreement (IAA) with

on $09 / 20 / 2010$.

Please remember that although you have an approved IAA you are required to submit a summary status update at the time that the annual continuing review would ordinarily be due. The status report should include any substantive changes made to the protocol in the intervening year, such as amendments or modifications, and any on-site serious adverse events.

Thank you.

Board Designee:

Letter Sent By: 9/20/2010 11:38 AM 


\section{APPENDIX B}

\section{CONSENTS FOR RESIDENT/POWER OF ATTORNEY}


To whom it may concern:

September 22, 2010

My name is Stephanie Meredith and I am a graduate student at West Virginia University. I am pursuing my Master's degree in Dental Hygiene. I am currently beginning work on my thesis which is titled "The Effects on the Oral Health Care of Residents Living in Long-Term Care Facilities with the Implementation of a Dental Protocol and Team." Your loved one was chosen to be evaluated for this study. If permission is granted I will conduct an assessment of your loved one's oral health needs. The assessment will consist of visual examination using a dental mirror. He or she will be evaluated at the beginning of the study, one month and three months. The staff responsible for dental care will attend an in-service relating to proper oral care and the effects of poor oral health.

I want to ensure you that your loved one will be treated kindly and very gently. His or her identity will remain anonymous throughout the study. My grandmother was a resident at a long-term care facility and it is in her honor that I chose this topic to study. I want to do all I can to allow residents like her to always keep the dignity they had when they were able to care for themselves.

Please return the enclosed consent form stating your decision. Please also take a minute to complete the survey attached. If you wish to discuss this any further feel free to contact me at Thank you for your consideration.

Respectfully, Stephanie Meredith 


\section{W. WestVurginiaUniversity.}

Office of Research Compliance

CONSENT AND INFORMATION FORM

Principal Investigator: Funk, Amy

Department:

DENTISTRY - Dental Hygiene

Tracking Number: $\quad \mathrm{H}-22676$

\section{Study Title:}

The Effects on the Oral Health Care of Residents Living in Long Term Care Facilities with the Implementation of a Dental Protocol and Team

\section{Co-Investigator(s):}

Meredith, Stephanie

\section{Sponsor}

\section{Contact Persons}

In the event you experience any side effects or injury related to this research, you should contact

If you have any questions, concerns, or complaints about this research, you can contact Stephanie Meredith at

For information regarding your rights as a research subject, you may contact the Office of Research Compliance at 304/293/7073.

\section{Introduction}

You, have been asked to participate in this research study, which has been explained to you by Stephanie Meredith $\mathrm{RDH}$. This study is being conducted by Stephanie Meredith at

. This research is being conducted to fulfill the requirements for a masters degree in Dental Hygiene in the Department of Dentistry at West Virginia University, under the supervision of Mrs. Amy Funk, MSDH.

\section{Purposes of the Study}

The purpose of this study is to learn more about the oral health care of residents living in long-term care facilities. WVU expects to enroll 30 subjects to participate in this study. 


\section{Description of Procedures}

This study involves conducting three separate visual exams, at baseline, one month and three months, using a mirror only to assess the oral health status of the residents. Each examination will take approximately three to five minutes to complete. You will be asked to fill out a questionnaire regarding your perception of the oral health status of you/your loved one. This will take approximately 10 minutes to complete. You do not have to answer all the questions. You will have the opportunity to see the questionnaire before signing this consent form.

\section{Risks and Discomforts}

There are no known or expected risks from participating in this study, except for the mild frustration associated with answering the questions.

\section{Alternatives}

You do not have to participate in this study.

\section{Benefits}

You may not receive any direct benefit from this study. Hopefully you see an improvement in the oral health status. The knowledge gained from this study may eventually benefit others.

\section{Financial Considerations}

This study involves no cost to participants and also will provide no payment.

\section{Confidentiality}

Any information about you that is obtained as a result of your participation in this research will be kept as confidential as legally possible. Although the participant's identity will not be used in the results of this study, there is some protected health information that may be collected and assessed during this study. This protected health information will include the participant's name, medical records and visual oral examinations and will be a part of the records collection process. The name will only be needed to keep the records with the correct participant so changes in the oral health status from the beginning to the end of the study will be accurate. In any publications that result from this research, neither your name nor any information from which you might be identified will be published without your consent. We know that information about you and your health is private. We are dedicated to protecting the privacy of that information. Because of this promise, we must get your written authorization (permission) before we may use or disclose your protected health information or share it with others for research purposes. Your research records, just like hospital records, may be subpoenaed by court order or may be inspected by federal regulatory authorities without your 
additional consent. You can decide to sign or not to sign this authorization section. However, if you choose not to sign this authorization, you will not be able to take part in the research study. Whatever choice you make about this research study, it will not have an effect on your access to dental care. This authorization will expire 6/1/11. I have read this section and all of my questions have been answered. By signing below, I acknowledge that I have read and accept all of the above.

or Authorized Representative Date

Signature of Participant

or Authorized Representative

Print Name of Participant

\section{Voluntary Participation}

Participation in this study is voluntary. You are free to withdraw your consent to participate in this study at any time. Refusal to participate or withdrawal will not affect your future care, and will involve no penalty to you. In the event new information becomes available that may affect your willingness to participate in this study, this information will be given to you so that you can make an informed decision about whether or not to continue your participation. You have been given the opportunity to ask questions about the research, and you have received answers concerning areas you did not understand.

Upon signing this form, you will receive a copy.

I willingly consent to participate in this research.

Printed Name

Date

Time

Subjects Legal Representative

The participant has had the opportunity to have questions addressed. The participant willingly agrees to be in the study. 
Tracking \#: $\quad$ H-22676

Approved On: $\quad$ 09/20/2010

Valid Through: $\quad$ 09/19/2011

Last Amended: N/A 


\section{APPENDIX C}

\section{QUESTIONAIRES}




\section{SURVEY FOR RESIDENT/POWER OF ATTORNEY}

1. Does your loved one require assistance with their oral health care?

YES NO NOT SURE

2. How would you rate their oral health?

\section{EXCELLENT GOOD FAIR POOR}

3. Prior to your loved one's admittance how important was good oral care to them?

VERY IMPORTANT IMPORTANT NOT IMPORTANT

4. Do you feel your loved one is suffering from dental pain?

YES NO NOT SURE

5. Do you think it would be beneficial to have a dental team on staff?

YES NO NOT SURE

COMMENTS: 


\section{QUESTIONAIRE FOR NURSING STAFF}

1. Do you assist the residents with their oral health care? YES NO

2. Of the following, circle all that you use with the residents.

TOOTHBRUSH TOOTHPASTE MOUTHRINSE DENTAL FLOSS

DENTURE BATH MOUTH SWABS OTHER:

3. Circle any hindrances you encounter when providing oral care?

PATIENT COOPERATION LACK OF SUPPLIES PROPER EDUCATION FEAR OF HARMING THE RESIDENT IACK OF SUPPORT

4. HOW MANY RESIDENTS DO YOU PROVIDE CARE FOR IN ONE DAY? LESS THAN $20 \quad 20-40 \quad 41-60 \quad$ GREATER THAN 60

5. What time of the day do the residents generally receive their oral care?

MORNING AFTER MEALS EVENING NIGHTTIME

6. Are you aware of the correlation between oral health and over all well-being? YES NO

7. Would you be open to an in-service on oral care methods?

YES NO

8. Do you feel having a dental team in a cooperative effort with the nursing staff would have a 
positive effect on the oral health of the residents?

YES NO

9. Did you receive any training on proper oral care when you were first employed?

YES NO

10. How would you rate your personal attitude toward dental health?

VERY IMPORTANT SOMEWHAT IMPORTANT $\quad$ DON'T CARE

Additional comments: 


\section{APPENDIX D}

\section{ORAL HEALTH ASSESSMENT TOOL}


ORAL HEALTH ASSESSMENT TOOL (OHAT) fOr LONG-TERM CARE

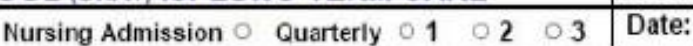

NOTE: A Star * and underine indicates referral to an oral heaith professional (i,e, dentist, dental hygienist, denturist) is required

\begin{tabular}{|c|c|c|c|c|c|c|}
\hline Category & $0=$ healthy & $1=$ changes & $2=$ unhealthy & Score & $\begin{array}{c}\text { Action } \\
\text { Required }\end{array}$ & $\begin{array}{c}\text { Action } \\
\text { Completed }\end{array}$ \\
\hline Lips & Smooth, pink, moist & $\begin{array}{l}\text { Dry, chapped, or red at } \\
\text { corners }\end{array}$ & $\begin{array}{l}\text { Swelling or lump, whitefred/uloerated } \\
\text { patch: bleedinal uberated at worners: }\end{array}$ & & $\begin{array}{l}1 \text { =intervention } \\
2=\text { refer }\end{array}$ & $\square Y E S \square N O$ \\
\hline Tongue & Normal, moist, pink & Patchy, fissured, red, coated & $\begin{array}{c}\text { Patch that is red andlor white } \\
\text { ulcerated, swollen: }\end{array}$ & & $\begin{array}{l}1=\text { intervertion } \\
2=\text { =refer }\end{array}$ & $\square$ YES $\square$ NO \\
\hline $\begin{array}{l}\text { Gums and } \\
\text { Tissues }\end{array}$ & $\begin{array}{l}\text { Pink, moist, } \\
\text { Smooth, no } \\
\text { bleeding }\end{array}$ & $\begin{array}{l}\text { Dry, shiny, rough, red. } \\
\frac{\text { swollen around } 1 \text { to } 6 \text { teeth. }}{\text { one ulcer or sore spot under }} \\
\text { denture: }\end{array}$ & $\begin{array}{l}\text { Swollen, bleeding around } 7 \text { teeth or } \\
\text { more. bese teeth ulcers andlier white } \\
\frac{\text { patches, generalized redness and/or }}{\text { tenderness: }}\end{array}$ & & 1 or $2=$ refer & $\square$ YES $\square$ NO \\
\hline Saliva & $\begin{array}{l}\text { Moist tissues, watery } \\
\text { and free flowing } \\
\text { saliva }\end{array}$ & $\begin{array}{l}\text { Dry, sticky tissues, little } \\
\text { saliva present, resident } \\
\text { thinks they have dry mouth }\end{array}$ & $\begin{array}{l}\text { Tissues parched and red, very little or } \\
\text { no saliva oresent saliva is thick. } \\
\text { ropey. resident complains of dir } \\
\text { mouth: }\end{array}$ & & $\begin{array}{l}1=\text { intervention } \\
2=\text { refer }\end{array}$ & $\triangle Y$ YES $\square$ NO \\
\hline $\begin{array}{l}\text { Natural } \\
\text { Teeth } \\
\square Y \square \mathrm{N}\end{array}$ & $\begin{array}{c}\text { No decayed or } \\
\text { broken teeth/ roots }\end{array}$ & $\begin{array}{l}\text { 1to } 3 \text { decaved ar broken } \\
\text { teeth/roots: }\end{array}$ & $\begin{array}{l}\text { A or mere decaved or broken teeth' } \\
\text { roots, or very worn down teeth, or } \\
\text { less than } 4 \text { teeth with co denturet }\end{array}$ & & 1 or 2 = refer & $\square Y E S \square N O$ \\
\hline $\begin{array}{l}\text { Denture(s) } \\
\square Y \square N\end{array}$ & $\begin{array}{l}\text { No broken } \\
\text { areas/teeth, dentures } \\
\text { worn regularly and } \\
\text { name is on }\end{array}$ & $\begin{array}{l}1 \text { broken area/tooth, or } \\
\text { dentures only wom for } 1 \text { to } 2 \\
\text { hours daily, or no name on } \\
\text { denture(s) }\end{array}$ & $\begin{array}{l}\text { More than } 1 \text { broken area/tooth } \\
\text { denture missing or not worn due to } \\
\text { Dear fit. or orwarnonlv with denture } \\
\text { adhesive: }\end{array}$ & & $\begin{array}{l}1=D \text { dentire } \\
2=\text { refer }\end{array}$ & $\square Y E S \square N O$ \\
\hline $\begin{array}{c}\text { Oral } \\
\text { Cleanliness }\end{array}$ & $\begin{array}{l}\text { Clean and no food } \\
\text { particles or tartar on } \\
\text { teeth or dentures }\end{array}$ & $\begin{array}{l}\text { Food particles/ tartar/ debris } \\
\text { in } 1 \text { or } 2 \text { areas of the mouth } \\
\text { or on small area of dentures; } \\
\text { occasional bad breath }\end{array}$ & $\begin{array}{l}\text { Food particles, tartar, debris in most } \\
\text { areas of the mouth or on most areas } \\
\text { of dentureisl, or severe halitosis (bad } \\
\text { breathi* }\end{array}$ & & $\begin{array}{l}1=\text { intervention } \\
2=\text { refer }\end{array}$ & $\triangle Y$ YES $\square$ NO \\
\hline \multirow[t]{2}{*}{ Dental Pain } & \multirow{2}{*}{$\begin{array}{l}\text { No behavioural, } \\
\text { verbal or physical } \\
\text { signs of pain }\end{array}$} & \multirow{2}{*}{$\begin{array}{l}\text { Verbal andlor behavioural } \\
\text { sians of oain such as oulling } \\
\frac{\text { of face chewing lips, not }}{\text { eating. agaression' }}\end{array}$} & \multirow{2}{*}{$\begin{array}{l}\text { Physical signs such as swelling of } \\
\text { cheef or aum broken teeth. ulcers. } \\
\text { 'gum boil', as well as verbal and of } \\
\text { behavioural signs" }\end{array}$} & & 1 or $2=$ refer & $\square Y E S \square N O$ \\
\hline & & & & \multicolumn{3}{|c|}{ Completed by: } \\
\hline \multicolumn{7}{|c|}{$\begin{array}{l}\text { FOLLOW UP } \\
\square \text { Oral Hygiene Care Plan - Date: } \\
\begin{array}{ll}\square \text { Person andior family/guardian refuses: a) } \square \text { Referral - Date: } & \text { Oral Health Assessment to be repeated on - Date: }\end{array}\end{array}$} \\
\hline
\end{tabular}




\section{CURRICULUM VITAE}

\section{EDUCATION}

1996 Wheeling Park High School

1998 Associate Degree Dental Hygiene, West Liberty State College

1999 Bachelor of Science Degree, West Liberty State College

2011 Masters of Science Dental Hygiene, West Virginia University

\section{PROFESSIONAL EXPERIENCE}

1998-present

Dental Hygienist

Wheeling, West Virginia

2009-present

Clinical Dental Hygiene Instructor

West Liberty University 